\title{
Impacts of Risks Over Benefits in the Adoption of Self-Tracking Technologies
}

\author{
Jean-François De Moya, EM Strasbourg Business School, France \\ Jessie Pallud, EM Strasbourg Business School, Université de Strasbourg, HuManiS, France \\ Samuel Fosso Wamba, TBS Business School, France \\ iD https://orcid.org/0000-0002-1073-058X
}

\begin{abstract}
Self-tracking (ST) technologies offer an unlimited number of opportunities to improve human life, especially health and well-being. Many scholars have been interested in this technology because of its worldwide spread but have not emphasized the benefits versus ST practices risks. This paper presents a literature review of the benefits and risks of ST practices to close this gap. It also develops a multidisciplinary research model based on the extended valence framework. This model offers five hypotheses highlighting the importance of considering technological, social, and health factors when measuring ST adoption. The results show that the perceived benefits outweigh the risks. Health is paramount in the perception of benefits. These results lead the authors to make a few recommendations for practitioners.
\end{abstract}

\section{KEYWORDS}

Adoption, Health, Literature Review, Self-Tracking, Valence Framework

\section{INTRODUCTION}

The adoption of technologies in the health sector has offered new possibilities to track physiological parameters and daily activities. In particular, self-tracking technologies (STTs) that are new Internet of Things (IoT) smart technologies (Joseph et al., 2017) provide plenty of opportunities for the empowerment of patients (Nelson et al. 2016) and for the healthcare sector, especially by generating data points to be collected and analyzed. For instance, through mobile applications, STTs help manage different diseases, such as diabetes, obesity, and asthma. Having citizens adopt STTs is an essential issue for the healthcare sector regarding the reduction of medical expenses (Rich \& Miah, 2017). A study conducted by Strategy Analytics indicates that smartwatch sales grew 20 percent in Q1 2020 (Waltzer, 2020). Indeed, since COVID 19, an increasing number of persons appreciates having a ST device capable of measuring their vital signs, such as oxygen levels.

While STT adoption is growing, and more academic research is being conducted on this topic (Ruckenstein \& Schüll, 2017), research has not paid enough attention to the multiple facets of STT adoption. Most of the research models in information systems (IS) that deal with STT are based on the Technology Acceptance Model (TAM) (Choi \& Kim, 2016; Chuah et al., 2016; K. J. Kim \& Shin, 2015; Wu et al., 2011) and thus acknowledge mainly technical factors (del Río Carral et al., 2017). In their literature review, del Río Carral et al. (2017) also point out that a purely technical approach does not reflect the complexity of self-tracking (ST) practices. They identify two trends in their review: 
1) a set of enthusiastic articles that promote STT as a new hope for health management and 2) more nuanced and critical articles that discuss this practice in light of a neoliberal surveillance society (e.g. De Moya and Pallud 2020). Examining STT requires a multidisciplinary approach (De Moya \& Pallud, 2017; Tuzovic, 2015) to involve health dimensions (with the promise of improved health), human and social dimensions (especially concerning privacy, human integrity, and normalization of society), and technical dimensions (regarding measurement reliability, a user-friendly interface design, and the methods used to analyze the collected data) (Lupton, 2016; Price et al., 2017). Becker et al. (2017) also suggest taking into account perceived benefits and costs that can influence the continued use of fitness trackers.

A stream of research in sociology deals with risks in society and individuals' avoidance strategies (Beck, 1992). Some risks are external, such as the risk of a nuclear accident (Beck, 1992). Others correspond to personal risks, such as smoking or eating too much fat or sugar. It is then up to the individuals to manage their own risks based on a benefit-cost calculation. To date, very few studies have focused on benefit-cost models for STT adoption. Therefore, this study is an initial attempt to bridge the existing knowledge gap in the literature. More precisely, the paper aims to address the following research questions:

- What are the perceived benefits and risks associated with STT?

- How do technological, social, and health determinants influence STT adoption?

To answer these research questions, the authors follow the works of Becker et al. (2017) and Gribel et al. (2016) on the acceptance factors of wearables. Additionally, the multidimensional perspective retained in this study is inspired by the research (Sheth et al., 1991) that takes into account different dimensions (such as functional, social, and emotional) to evaluate product value. According to Sheth et al. (1991), each of these values exerts a relative influence on the purchasing decision. Similarly, the authors would like to assess how different dimensions influence the decision to adopt STT.

The paper is structured as follows. Section 2 presents a literature review on the risks and the benefits of STTs. Section 3 introduces the extended valence framework, and the concept of risk from an IS perspective. Section 4 explains the development of the comprehensive research model. The methodology is detailed in Section 5, and the results are presented in Section 6. The final sections provide a discussion of the research outcomes, as well as suggestions for future research.

\section{RISKS AND BENEFITS OF SELF-TRACKING}

\subsection{Definition of Self-Tracking Technologies}

This research focuses on adopting and using two types of STTs, namely mobile health applications (apps) and wearables, which is presented in the following two subsections.

\subsubsection{Mobile Health and Mobile Health Apps}

Mobile health (mHealth), at the intersection of electronic health and smartphone technology (Adibi, 2015), enables data collection with sensors that are either integrated into the mobile technology or connected to the mobile devices via wireless or wired connections. The data are then manipulated with smartphone apps and transmitted to third parties via the cloud infrastructure. Technically, the sensors used by smartphones are the same as those in smartwatches or activity bracelets. A smartphone equipped with a tracking app can measure the physical parameters of an individual.

The mobile health tracking app is part of mHealth, defined as "medical and public health practice supported by mobile devices, such as mobile phones, patient monitoring devices, personal digital assistants and other wireless devices" (WHO Global Observatory for eHealth \& World Health 
Organization, 2011). The mHealth tracking app generally includes wellbeing and fitness apps, which track steps and calories, lifestyle information, such as sleep, and stress management.

\subsubsection{Wearables}

Wearable technology refers to clothing or accessories produced or improved with electronics (Sinha \& Gupta, 2019). This intelligent portable system or "smart wearable system" (Chan et al., 2012), which consists of sensors for capturing data and then storing and transmitting data on the cloud, either standalone or via a smartphone (Weber, 2015).

There are two categories of wearable materials. The first is portable technology, allowing people to use the device unobtrusively (Barth, 2013). The second category comprises intelligent textiles, integrating the technology into the fabric itself (Page, 2015). The primary purpose of these tools is to measure and/or react to environmental stimuli (Van Langenhove et al., 2012).

Fitness trackers are worn wrist bracelets that track fitness activities (steps and calories) and the users' health in real-time (Yang et al., 2016). They are also known as activity trackers, wearable fitness trackers, wearable fitness technology, smart wristbands, or smart bracelets. The primary purpose of these devices is to collect data that a user can analyze on different devices (e.g., laptop computer or smartphone). The presentation of information is very limited (e.g., pulse or time), and smart wristbands do not offer the possibility to install apps (Chuah et al., 2016).

A smartwatch is a kind of fitness tracker with extended functionalities, such as alert notifications (Gay \& Leijdekkers, 2011). It is larger in size than smart wristbands and often even larger than most traditional watches. "The face of a smartwatch is usually a touchscreen. An operating and app ecosystem allows users to install various apps. It's a mini device that is worn like a traditional watch and allows for the installation and use of applications" (Yang et al., 2016, p. 277).

In addition to fitness trackers and smartwatches, the following terms were used to review the literature:

- Healthcare wearable: tracker used in a healthcare aim (diabetes, electrocardiogram, symbiotic system, etc.) (Shafi \& Waheed, 2019), also known as a personal health device, wearable biomedical sensor, self-tracking technology for health fitness and wellbeing, sensor-based global health technology, wearable technology in healthcare, wearable device-based pervasive wellbeing monitoring, and smart healthcare fabric.

- General wearable: wearable technology that does not mention any detail on the device, also known as wearable ubiquitous monitoring device, body-worn sensor system, smart wearable device, and self-tracking device.

\subsection{Literature Review on The Benefits and The Risks of STT}

The topic of ST has been researched across various disciplines that can be grouped into three domains: technological (IS, computing science, etc.), medical, and social sciences (marketing, sociology, etc.) (De Moya \& Pallud, 2017).

The researchers performed a literature search on STT adoption using several databases, namely Business Source Premier, Science Direct, Web of Science, IEEExplore, and Google Scholar. As STT is a generic term, several adjacent keywords were also used for the query, such as: "activity tracking device," "fitness tracker," "physical activity tracking," "healthcare device," "mhealth," "wristband," and "wearable." These keywords were used in conjunction with the terms "adoption," "appropriation," "acceptance," "perception," "continuity," "commitment," "attitude," and "motivation." The search was limited to peer-reviewed articles and excluded editorials, books, and magazine articles. 
Table 1. Research publications on self-tracking tool adoption between 2008 and 2017

\begin{tabular}{|c|c|c|c|c|c|c|c|}
\hline \multirow[b]{3}{*}{$\begin{array}{l}\text { Period of } \\
\text { publication }\end{array}$} & \multicolumn{7}{|c|}{ Tool } \\
\hline & \multicolumn{4}{|c|}{ Wearable } & \multirow{2}{*}{$\frac{\text { mHealth }}{\text { Mobile App }}$} & \multirow[b]{2}{*}{$\begin{array}{l}\text { Multiple } \\
\text { Types }\end{array}$} & \multirow[b]{2}{*}{ Total } \\
\hline & $\begin{array}{l}\text { Fitness } \\
\text { Tracker }\end{array}$ & Smartwatch & $\begin{array}{l}\text { General } \\
\text { wearable }\end{array}$ & $\begin{array}{l}\text { Healthcare } \\
\text { wearable }\end{array}$ & & & \\
\hline 2008-2009 & 0 & 0 & 0 & 2 & 0 & 0 & 2 \\
\hline 2010-2011 & 0 & 0 & 2 & 0 & 1 & 0 & 3 \\
\hline $2012-2013$ & 0 & 0 & 3 & 3 & 2 & 0 & 8 \\
\hline 2014-2015 & 7 & 1 & 3 & 5 & 10 & 0 & 26 \\
\hline $2016-2017$ & 9 & 6 & 10 & 2 & 6 & 4 & 37 \\
\hline
\end{tabular}

\subsubsection{Findings}

The search yielded 75 peer-reviewed research publications. Most research focuses on a single technology, especially fitness trackers and mobile apps. Several studies do not specify what type of wearable is being examined and simply define the technology in a general way (Table 1).

Considering the significant variables found in the 75 articles, the authors have grouped the factors affecting STT into three categories: health, social, and technological dimensions. These findings are discussed in more detail in Section 4 when developing the research model. The main factors are combined with the extended valence framework introduced in the next section.

A number of studies have applied the theory of reasoned action (TRA) or its extension, the theory of planned behavior (TPB), to examine consumer behavior toward STT (Herrmann \& Kim, 2017; Jia \& Kim, 2015; Melzner et al., 2014). Some studies have combined these models with specific theoretical constructions from the STT literature. For instance, Jia and Kim (2015) offer a TPB-based model that includes attitude, subjective norm, control of perceived behavior, and the influence of social media. They combine this model with the theory of diffusion of innovation (DOI). Their model is designed to understand the adoption of smartwatches, such as the Apple Watch.

Moran et al. (2013) have built a model to compare the British and the Japanese adoption of ubiquitous surveillance devices. They use the TPB combined with attitude toward technology, as well as attitude toward apps, as an antecedent to attitude toward behavior and behavioral intention to use the technology.

The technology adoption model (TAM) has been created to explain why individuals accept technology in the workplace (Davis, 1989). Several researchers have extended the TAM-based model to explain STT adoption by accounting for technological and behavioral aspects (Gao et al., 2016; Kim \& Shin, 2015; Lunney et al., 2016; Spagnolli et al., 2014). For example, to explain the adoption of smartwatches, Chuah et al. (2016, p. 278) have added a new variable, namely visibility, defined as "a person's beliefs about the extent to which smartwatches are noticed by others (Fisher \& Price, 1992)." Baudier et al. (2020) examined the variables impacting (or not) attitude towards using a smartwatch relying on the TAM and two additional variables, namely perceived connectivity and perceived usefulness.

Developed by Venkatesh et al. (2003), the unified theory of acceptance and use of technology (UTAUT) provides a unified view of eight models extensively used in IS, comprising the TPB and the TAM. Pfeiffer et al. (2016) have added a reflexive dimension to the UTAUT, which consists of trust, perceived aesthetics, and personal innovativeness, to study STT adoption. This addition is supposed to reflect the human-machine interaction better.

Introduced by Bandura (1986), the social cognitive theory (SCT) anticipates that individuals will become motivated and guide their actions through their beliefs and self-efficacy (O'Brien et 
Figure 1. Frequency of occurrence of the prevailing adoption theories in the STT literature

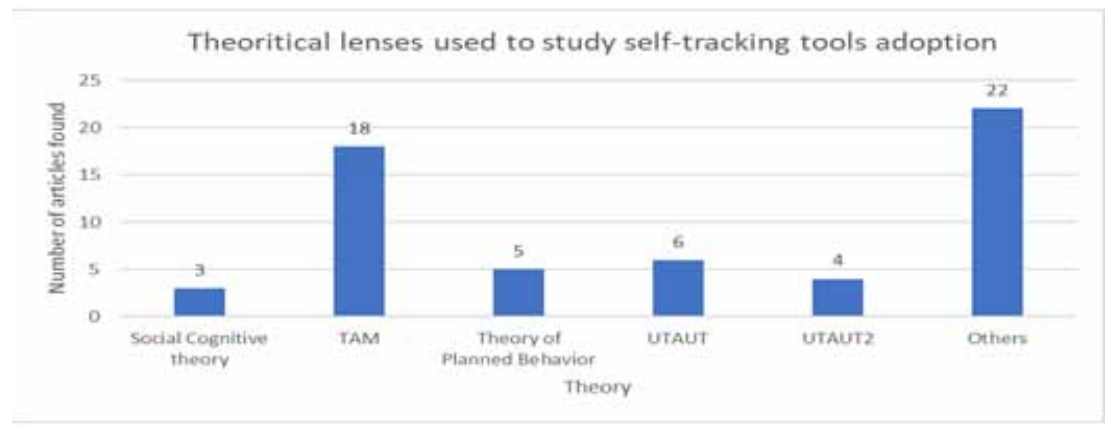

al., 2015). The SCT is used in conjunction with other models to explain the behavior to maintain a physical activity or to encourage changing a behavior. Researchers relying on the SCT want to explain how STT leads to self-efficacy. For example, Ehlers and Huberty (2014) incorporate both the SCT and the UTAUT to examine user preferences for mobile physical activity apps. Self-regulation has emerged as a variable that improves physical activity.

The literature shows a wide variety of explanatory variables that do not belong to any of the categories commonly used in the IS literature, but they appear in other fields, such as user experience modeling. The STT literature is transversal, so it includes many theories from psychology or medicine, with theories on motivation (Gimpel et al., 2013; Shin \& Biocca, 2016), the theory of persuasion (Shih et al., 2015), and the self-efficacy of technologies in behavioral change (Park et al., 2015). Beyond the adoption of technologies, researchers also question the usefulness of STT for health and wellbeing management, which are the top promises made by manufacturers of self-tracking devices. For instance, Shin and Biocca (2016) use the Transtheoretical Model (TTM) and the expectation confirmation theory (ECT) to explain pre and post-adoption. The TTM is generally used to explain why an individual changes one's behavior. Figure 1 summarizes the frequency of occurrence of the five prevailing adoption theories that appear in the literature analysis.

Appendix A shows that very few studies have mobilized technological, medical, and social aspects together. Appendix B represents the variables' ranking: ease of use, utility, and standards are the most common themes in the literature. Attitude toward technology and behavioral intention to use ST tools are widely used variables. This underlines the importance of TAM in the analysis of STT acceptance. Due to space limitations, Appendix B is restricted to the most cited variables in a maximum of three publications. Several constructs have only been found once or twice in the literature. This volume corresponds to 121 variables from a total of 144 variables. Taking into account the significant variables found in the 75 articles, the researchers have done a two-level classification that can be found in Appendix C. The first level contains three themes: 1) the tool's characteristics and user perceptions of these characteristics, 2) the person's characteristics, and 3) social concerns. At the second level, we specified sub-dimensions and the number of variables used in the literature.

\section{THE CONCEPT OF RISK IN IS RESEARCH}

Risk is a concept that is studied in many different disciplines, such as economics, psychology, or marketing (Bauer, 1967). In IS, risk is often used to explain IS usage or intentions to use them, for example, in e-commerce (Doolin et al., 2005, Dinev et al., 2006, Mou et al., 2020), because this variable has a significant influence on user perceptions (Cocosila et al., 2009; Featherman \& Pavlou, 2003). Actually, technologies can be compared to a black box whose content is unknown to the user because the information is sometimes unavailable to explain the functioning of the technology. This 




lack of information translates into a perceived risk for users (Cocosila et al., 2009). Moreover, IS raises security issues, whether they occur during an electronic transaction when paying on a merchant's website (Dinev et al., 2006; D. J. Kim et al., 2008; Y.-H. Li \& Huang, 2009; Lian \& Yen, 2014; Verhagen et al., 2006) or when using an online service (Horst et al., 2007; M.-C. Lee, 2009; Martins et al., 2014). These risks are generally measured with six dimensions (see Appendix D), such as privacy risk or source risk, that is, the risk related to the lack of knowledge of the seller's reputation (Lim, 2003). Risk is a concept that can be found in many IS articles, of which a few examples is cited in Appendix E.

To analyze the role of risk, some researchers rely on the valence theory (Peter \& Tarpey Sr., 1975). According to Kahneman and Tversky (2013), this theory originates from the established school of thought, named the rational choice theory, which considers that individuals act in accordance with a utilitarian logic based on the evaluation of costs and benefits. After doing calculations, individuals evaluate the costs and the benefits of the solutions considered in order to maximize their overall benefit. This theory has been used in IS to explain user behavior in a variety of situations, such as the perception of security information or the choice of a password (Aytes \& Connolly, 2004; Bulgurcu et al., 2010). These cited authors explain that complying with the rules tends to produce benefits, while non-compliance can lead to costs. Lee (2009) has developed a model based on the valence theory to measure technology adoption in an e-trading context. The perceived security risk of banking transactions is balanced by the perceived benefit of using an online service that reduces transaction costs and allows greater responsiveness.

Kim et al. (2009) have extended this theory in the marketing context to account for the role of trust in risk/benefit evaluation and to measure the impact on customer intentions (see Figure 2). Mou et al. (2016) have relied on this extended version of the valence theory in conjunction with the Health Belief Model (Rosenstock, 1974) to theorize the adoption of online health services. Mou et al. (2016) define risk as the sum of performance-related risks, psychological risks, and perceptions on the time needed to search for health information. This sum of risks is counterbalanced by the consumer belief that online health information could improve one's health condition (perceived benefits). Their results confirm that the benefits positively influence the intention to use ST tools and that the risks negatively affect the adoption of digital health services. Their results also prove the role of trust in positively influencing intentions, reducing risk perceptions, and increasing perceived benefits.

\section{DEVELOPING THE THEORETICAL MODEL}

Drawing on the Extended Valence Framework and the literature review on the risks and the benefits of STT adoption, a comprehensive research model has been developed (Figure 3). This section presents the hypotheses by explaining the assumptions that have led to the construction of this model. It is hypothesized that trust will influence individuals' perceptions of risks and benefits and 

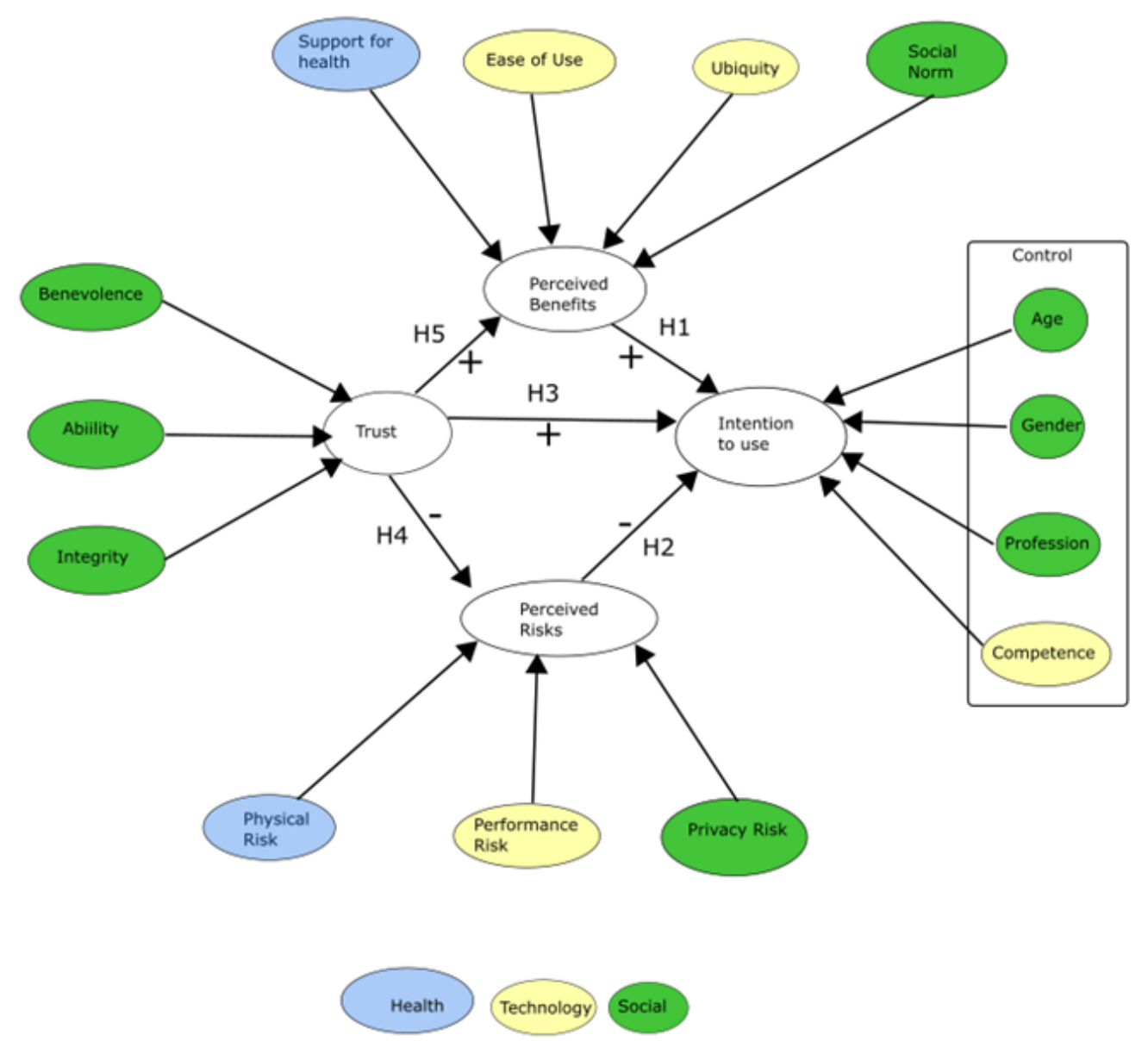

their intentions to use the technology. Perceived benefits comprise health support, ubiquity, ease of use, and social norms, which all have a positive impact on the intentions to use STT. Perceived risks include physical, performance, and privacy risks. The risks and the benefits that are integrated into the model represent the most salient factors identified in the literature. They also cover well the three dimensions (health, social, and technological) presented in Figure 3 below.

\subsection{Perceived Benefits}

Two technological factors are retained to measure perceived benefits, namely perceived ease of use and ubiquity. Perceived ease of use refers to "the extent to which the potential user expects the target system to be free of any user effort" (Davis, 1989, p. 320). Prior research has demonstrated the positive effect of ease of use on the intention to use STT (Lunney et al., 2016; Pfeiffer et al., 2016). A qualitative study also highlights users' need for simple and easy to use STT (Canhoto \& Arp, 2017). Following this reasoning, it can be assumed that this factor is a component of perceived benefits and can encourage the intention to use STT. Since STT belongs to the category of mobile technologies, users will generally expect mobile features or the possibility to have a ubiquitous 
Table 2. Benefits of self-tracking

\begin{tabular}{|c|c|c|}
\hline Dimension & Factor & Articles \\
\hline \multirow{7}{*}{ Health } & Disease management & $\begin{array}{l}\text { (Swan, 2009; Majmudar et al., } 2015 \text {; Becker, } \\
\text { Matt, Widjaja, \& Hess, 2017) }\end{array}$ \\
\hline & Assistance to the elderly & (Majmudar et al., 2015) \\
\hline & Self-awareness & $\begin{array}{l}\text { (Choe et al., } 2015 \text {; Sharon et Zandbergen, } \\
\text { 2017) }\end{array}$ \\
\hline & $\begin{array}{l}\text { Support for Physician-patient } \\
\text { communication }\end{array}$ & (Ruckenstein, 2015; Majmudar, 2015) \\
\hline & Increase physical activity & (Barret et al., 2013 ; Pfeiffer et al., 2016) \\
\hline & Increase one's potential & (Lupton, 2013 ; Swan, 2013) \\
\hline & Self-control & (Lupton D. 2014; Pfeiffer et al. ,2016) \\
\hline \multirow[b]{2}{*}{ Social } & Motivation through data sharing & (Swan, 2009; Stragier et al., 2015) \\
\hline & $\begin{array}{l}\text { Social acknowledgement through } \\
\text { self-management, and self-image }\end{array}$ & $\begin{array}{l}\text { (Lupton, 2015; Crawford et al., 2015; Mercer } \\
\text { K. et al. 2016; Becker et al., } 2017 \text {; Peng et } \\
\text { al., 2016 ; Chuah et al., 2016) }\end{array}$ \\
\hline \multirow[b]{2}{*}{ Technology } & Ease of use & $\begin{array}{l}\text { (Canhoto \& Arp, } 2017 \text {; Lunney et al., 2016) } \\
\text { (Melzner et al., } 2014 \text {; Chuah et al., 2016) }\end{array}$ \\
\hline & Ubiquity & $\begin{array}{l}\text { (Gimhae, 2013; Kim \& Shin, 2015; Jung et al., } \\
\text { 2016; Hirose \& Tabe, 2016 ; Gribel et al., } \\
\text { 2016; Neill et al., 2016) }\end{array}$ \\
\hline
\end{tabular}

experience. Ubiquity is characterized by time and space flexibility and defined as the opportunity "to monitor user conditions anytime and anywhere" (Hirose \& Tabe, 2016, p. 48; see aksi Okazaki et al., 2009). Ubiquity positively influences users' perceptions when they use STT (Hirose \& Tabe, 2016; Kim \& Shin, 2015) and contributes to the perceived usefulness of the wearable device (Gribel et al., 2016). Therefore, ubiquity is another component of perceived benefits.

The various health-related benefits can be combined into a single variable called health support, defined as "the perception of portable self-care devices to support the treatment of health problems" (Pfeiffer et al., 2016, p. 6). Indeed, the intrinsic objective of ST, as given by its definition, is to improve health. Besides, monitoring one's health is one of the main reasons for explaining the purchase of STT devices (M. Becker et al., 2017). Therefore, health support represents an important sub-construct to assess perceived benefits.

Lastly, perceived benefits include social benefits, namely social norms, defined as "the extent to which consumers believe that other important people (e.g., close friends and family) believe they should use a particular technology" (Venkatesh et al., 2012, p. 159). This factor has been extensively tested in the research stream of technology adoption. Social norms originate from the TPB and describe the social pressure to behave in a certain way (Ajzen, 1991). Past research indicates that ST practice is a response to social pressure (M. Becker et al., 2017; Crawford et al., 2015; Peng, Kanthawala, et al., 2016) and that this social pressure positively influences the intention to use STT (Gilbert \& Namagembe, 2013; Pfeiffer et al., 2016; Yoganathan \& Kajanan, 2014).

The benefits of self-tracking are summarized in Table 2 .

These three different benefits, combined together, constitute an overall perception of the perceived benefits, which positively influence the intention to use STT, in accordance with the Extended Valence Framework (Kim et al., 2009; Mou et al., 2016). Therefore, the following hypothesis was posited: 
H1: Perceived benefits positively influence the intention to use STT.

\subsection{Perceived Risks}

Performance risk is defined as "the possibility that the product will malfunction and not function as designed and advertised and, therefore, fail to provide the desired beneðt" (Grewal et al., 1994, p. 145). Thus, when the STT is not representative of someone's own activity, one will stop using it (Buchwald et al., 2015; Wen et al., 2017). Additionally, some tools lack the ability to automatically detect user activity (for example, practicing a sport, sitting, or sleeping is not always captured well by the technology). This leads to the manual entry of the data, which is time-consuming and tends to have a negative impact on ST practices (Almalki et al., 2015). As such, the lack of performance contributes to a perceived risk of using monitoring tools.

The different health risks can be combined into a single variable named physical risk, which is defined as "the possibility that products may be harmful to the health of individuals or those products may not look as good as individuals expect" (Lim, 2003, p. 219; see also Jacoby \& Kaplan, 1972). It can be operationalized in terms of wearable discomfort (M. Becker et al., 2017; Shih et al., 2015) or techno-stress (Spagnolli et al., 2014). Consequently, the perceived physical risk is a factor that negatively affects the intention to use ST.

The third risk that is frequently mentioned in the literature is the privacy risk, which is defined as "potential loss of control over personal information, for example when information about you is used without your knowledge or permission" (Featherman \& Pavlou, 2003, p. 455). This risk is amplified by the fact that ST data tend to be hosted on the cloud (Lupton, 2015), making it vulnerable and reusable by third parties. For example, health and wellbeing apps available in ST devices share or exchange data with third parties, and several large insurance companies are also partnering with health app developers (Dredge, 2013). Privacy risk represents an additional attribute of perceived risk.

The risks of self-tracking are summarized in Table 3.

These combined three risks reflect an overall perception of the perceived risks. In accordance with the Extended Valence Framework (D. J. Kim et al., 2009; Mou et al., 2016), the authors posit the second hypothesis:

H2: Perceived risks negatively influence the intention to use STT.

\subsection{Trust}

Trust is defined as "the belief that the other party will behave in a socially responsible manner, and, by so doing, will fulfill the trusting party's expectations without taking advantage of its vulnerabilities" (Pavlou, 2003, p. 74; see also Gefen, 2000). Research has shown that this variable is often associated with different risks that influence the intention to use technologies (Gao et al., 2016; Mou, 2015). As such, ST research has consistently identified trust as playing a role in ST adoption (Greenfield et al., 2016; Shih et al., 2015), but few studies have used it in quantitative models (e.g., Jusob et al., 2016).

Due to the fact that self-monitoring systems continually collect data from users, the latter needs to trust the provider, especially its ability to guarantee data security (Gefen et al., 2003). Trust has been questioned several times when examining ST (Altenhoff et al., 2015; Gao et al., 2016; Pfeiffer et al., 2016). This is mainly due to a certain opacity of manufacturers that rarely explain their methodology to detect and measure physical activities (Shih et al., 2015). Users will often triangulate with physicians to validate the effectiveness of their monitoring applications (Peng, Yuan, et al., 2016). Conversely, users who do not trust the data collected by ST devices tend to reject the technology and to favor assessments conducted in the hospital (Sun \& Rau, 2015).

In the Extended Valence Framework (Kim 2009) and in studies on monitoring tools (Gao et al., 2016; Jusob et al., 2016; Mou et al., 2016; Pfeiffer et al., 2016), trust is a variable that directly affects the intention to adopt ST devices. Consequently, the following hypothesis was posited: 
Table 3. Risks of Self-Tracking

\begin{tabular}{|c|c|c|}
\hline Dimension & Factor & Article \\
\hline \multirow{4}{*}{ Health } & Techno-stress & (Spagnolli et al., 2014) \\
\hline & Vulnerability to disease & (Gao et al., 2015; Melzner et al., 2014) \\
\hline & Impact from disease & (Becker et al., 2017 ; Melzner et al., 2014) \\
\hline & Discomfort & (Shih et al., 2015 ; Becker et al., 2017) \\
\hline \multirow{4}{*}{ Social } & Privacy & $\begin{array}{l}\text { (Mackert et al., } 2016 \text {; Illiger et al., } 2014 \text {; Guo et al., } \\
2012 \text {; Greenfield et al., } 2016 \text {; Jusob et al., } 2016 \text {; Sul } \\
\text { \& Rau, } 2015 \text {; Cheng \& Mitomo, } 2017 \text {; Li et al., } 2016 \\
\end{array}$ \\
\hline & Trust & $\begin{array}{l}\text { (Shih et al., } 2015 \text {; Buchwald et al., } 2015 \text {; Jusob et al. } \\
2016 \text {; Peng et al., } 2016 \text {; Yoganathan \& Kajanan, } \\
2014 \text {; Altenhoff et al., } 2015 \text {; Gribel et al., } 2016 \text {; } \\
\text { Pfeiffer et al., } 2016 \text {; Sun \& Rau, } 2015 \text {; Gao et al., } \\
\text { 2016) }\end{array}$ \\
\hline & Third-Party Surveillance & (Lupton, 2013; Ruckenstein et Schüll, 2017) \\
\hline & Normalization & (En et Pöll, 2016) \\
\hline \multirow{2}{*}{ Technology } & $\begin{array}{l}\text { Waste of time in data manage- } \\
\text { ment }\end{array}$ & (Rapp et Cena, 2016 ; Almalki et al., 2015). \\
\hline & Data reliability & $\begin{array}{l}\text { (Becker et al., 2017; Coorevits \& Coenen, 2016; Shih } \\
\text { et al., 2015; Buchwald et al., 2015; Wen et al., 2017) }\end{array}$ \\
\hline
\end{tabular}

H3: Trust positively influences the intention to use STT.

The valence model also points out the effects of trust on perceived benefits and perceived risks. For instance, users of monitoring tools express the role of trust in risk perception (Gribel et al., 2016). In other areas, such as e-commerce, the higher the confidence in the seller, the lower the perceived risk appears to be (Gefen et al., 2003). This leads to the following hypothesis:

H4: Trust reduces perceived risks.

E-commerce studies show that trust positively influences a product's perceived usefulness (e.g., Gefen et al., 2003). More precisely, the more credible the seller's image is, the more the buyers perceive the promise of a perceived benefit. According to Mou et al. (2016), trust also influences the perceived benefit of using online health services, hence the following hypothesis:

H5: Trust increases the perceived benefits of using STT.

\section{METHODOLOGY AND DATA COLLECTION}

\subsection{Scale Measurement}

The measurement scales were developed relying on the literature. The items were then modified to fit the ST context. All constructs were measured with at least three indicators and a 7-point Likert scale, which is more reliable than the 5-point scale (Maydeu-Olivares et al., 2017). Intention to use STT was measured with the scale that Pfeiffer et al. (2016) employed in their ST study. For trust, the 
authors chose a three-dimensional formative construct inspired by Mayer et al. (1995) and used by Mou and Cohen (2014) in the context of online health services.

Health support was measured with the scale developed by Pfeiffer et al. (2016). The items cover health awareness, disease prevention, and stimulation of physical activity to maintain a healthy lifestyle. We added cognitive support, which contributes to people's good health. Ubiquity was measured using the scale employed by Hirose and Tabe (2016) based on that of Okazaki and Mendez (2013). Ease of use was measured with the scale used by Pfeiffer et al. (2016) based on those of Venkatesh et al. (2003), Lu et al. (2005), and Gefen et al. (2003). Social influence was measured using the scale of Pfeiffer et al. (2016) based on that of Venkatesh et al. (2012). These items introduce the notion of sharing and comparing ST data as motivators (Stragier et al., 2015).

The physical risk was measured with the scale employed by Gurtner (2014). Based on the work of González Mieres et al. (2006), the scale was used by Gurtner (2014) in a study on resistance to mobile health applications. Performance risk was measured with the scale applied by Yang et al. (2016). Used in the adoption of wearables, this scale was based on those of Grewal et al. (1994) and Stone and Grønhaug (1993). Privacy risk was measured with the scale of Li et al. (2016), who used it for the adoption of health wearables. The survey is shown in Appendix F.

\subsection{Second-Order Concepts}

The risk model is based on three second-order formative constructs (C. Ringle et al., 2015) representing profit, risk, and trust. To operationalize them, we use a two-step approach called the "sequential method of repetition score of the factors that compose the latent variables" (Becker et al., 2012; Ringle et al., 2012). The first step is to add the set of first-order manifest variables to the second-order latent variables, as shown in Appendix G. In the second step, the model is computed, and the scores of the latent variables are recorded in a file. A new model is created, containing only the second-order latent variables. The score of the first-order variables is used as the formative manifest variables for the second-order latent variables (Appendix $\mathrm{H}$ ). This method generates the value of $\mathrm{R}^{2}$ and indicates the influence of the other variables (J. Hair et al., 2016).

\subsection{Data Collection Procedure}

The authors conducted an online survey from two different sources. A portion of their sample came from Facebook. Using a social network has the advantage of returning a wide range of profiles through the snowball mechanism (Biernacki \& Waldorf, 1981) in a relatively short period of time. The questionnaire was posted online from November $1^{\text {st }}$ to November $30^{\text {th }}, 2018$, and received 210 responses. The second data source was a European university, where the authors administered the questionnaire to 118 students. They, therefore, received a total of 328 responses. Having these two different sources for data gathering offers more diversity in terms of the age range. The questionnaire began with a description of the tracking tools and cited examples of products, such as Fitbit and Apple Watch. The data were analyzed using SmartPLS software. The researchers followed the recommendations (Gefen et al., 2000) on a sample size at least ten times larger than the size of the most complex construct. In their model, perceived benefit represents the most complex construct. It is composed of 18 items, forcing us to have a minimum of 180 responses.

\section{DATA ANALYSIS}

The data were filtered to keep only those questionnaires that were completed in their original form. As a result, 83 questionnaires were deleted. Then, we removed all the questionnaires from the respondents with no knowledge of self-monitoring technologies. Nine questionnaires were thus withdrawn. The usable sample consists of 236 questionnaires in total.

The authors employed SmartPLS 3.0 software to analyze the data (C. Ringle et al., 2015). Several reasons led us to favor the Partial List Squares technique. First, the model is composed of formative 
constructs. This type of construct is particularly adapted to a PLS approach. Second, the model is complex due to its 11 constructs. Finally, the size of our sample is small, and the data do not respect a normal distribution.

\subsection{Descriptive Analysis}

The descriptive analysis of the sample indicates a greater presence of women (62\%) than men (38\%) (Table 4). The average age is relatively young (31 years old), due to half of the sample comprising first-year bachelor's degree students. Users represent $27 \%$ of the entire sample, that is, nearly 3 out of 10 individuals, which should be compared with market statistics, that is, $12 \%$ of the French own a connected bracelet or watch (OpinionWay, 2017). The results are, therefore, comparable with those of the market. Among the technologies, mobile apps are the most widely used, with $27 \%$ of the people reporting having used a mobile app.

\subsection{Data Distribution}

Although PLS is a method that does not require a "normal" distribution of data, it is still recommended to check that the distribution should not deviate excessively from the normal range (J. Hair et al., 2016). To test the validity of the distribution, Hair et al. (2016) suggest checking that the skewness indicator (skewness of the distribution) and the kurtosis indicator (width of the distribution) remain within a value between -1 and +1 . When the skewness indicator is greater than 1 , it means that the distribution is skewed to the right, and when the indicator is less than 1, it means that the curve is skewed to the left. A kurtosis value greater than 1 means that the curve is too sharp, and a value less than 1 means that the curve is too flat. The table in Appendix D provides the indicator values for the different items. It shows that EOU2, EOU3, and UB1 are too narrow compared with a normal distribution. However, since the degree of kurtosis does not deviate much and since these items are part of a reflective scale that contains other items, this deviation is not considered a problem, so these items were retained.

\subsection{Reliability and Validation of Scales}

In the PLS approach, construct validity is generally measured by discriminant validity and convergence validation (Gefen \& Straub, 2005). Convergence validity confirms that each item is correlated with the theoretical construct. Discriminant validity confirms that these items are weakly related to the other theoretical constructs. Several measurement techniques exist, and the authors follow Gefen and Straub's (2005) recommendation to verify both levels of validity.

Convergence validity (i.e., the estimate that an indicator is correlated with other indicators of the same construct) is assessed by the external load and the average variance extracted (AVE). Appendix I shows the different results. An indicator is considered representative if its T-value is greater than 1.96 and its load is greater than 0.7 (Hair et al., 2016; Nunnally \& Bernstein, 1967). Only one item does not meet this threshold, namely item \#2 of performance risk (PER2). According to the recommendations of Hair et al. (2016), the item can be removed if doing so improves internal reliability. After the removal of the indicator, the calculations show no improvement. The authors have therefore decided to keep it. The AVE values are between 0.539 and 0.867 , which are above the recommended threshold of 0.5. This means that on average, the construct explains more than half of the variance of the indicators comprising it. The internal consistency of the constructs is tested with the reliability indicator (composite reliability). The results show values above the recommended threshold of 0.7 .

For discriminatory validity, it is necessary to check that the indicators only represent the constructs to which they refer. Appendix $\mathbf{J}$ shows that all factors are defined only in their constructs and do not overlap with the others. Therefore, the results confirm the convergence of the items. Table 5 presents the discriminatory validity of the constructs of the Fornell-Larker test (Fornell \& Larcker, 1981). The square roots of the AVE are in bold font on the diagonals. The other numbers represent the correlation 
Table 4. Descriptive analysis of the sample

\begin{tabular}{|c|c|c|}
\hline & & $\mathbf{N}$ \\
\hline Complete & & 245 \\
\hline Users $(\%)$ & & $87(27 \%)$ \\
\hline Non Users (\% Yes) & & 158 \\
\hline Exploitable & & 236 \\
\hline \multirow{7}{*}{ Competence } & Extremely incompetent & 24 \\
\hline & Mid competent & 26 \\
\hline & Slightly incompetent & 15 \\
\hline & Neutral & 88 \\
\hline & Slightly competent & 36 \\
\hline & Mid competent & 36 \\
\hline & Extremely competent & 11 \\
\hline Mean Age (SD) & & $31(15,5)$ \\
\hline Male (\%) & & $90(38 \%)$ \\
\hline Female & & $146(62 \%)$ \\
\hline \multirow{2}{*}{ Country } & France & $218(92 \%)$ \\
\hline & Other & $18(8 \%)$ \\
\hline \multirow{7}{*}{ Profession } & Artisan & 10 \\
\hline & Higher intellectual profession & 44 \\
\hline & Middle profession & 30 \\
\hline & Employee & 26 \\
\hline & Worker & 4 \\
\hline & Student & 111 \\
\hline & Other & 7 \\
\hline
\end{tabular}

between the latent variables. Discriminative validity is checked if the numbers on each row and column are less than the values in bold on the corresponding row or column. The cross-correlation table and the Fornell-Larker test confirm that the indicators represent only their constructs.

Podsakoff, MacKenzie, and Podsakoff (2012, p.565) explain that "method biases can significantly influence item validities and reliabilities as well as the covariation between latent constructs. This suggests that researchers must be knowledgeable about the ways to control method biases that might be present in their studies." To address the issue of common method bias, we tested for multicollinearity by calculating the variance inflation factor (VIF) values. We used in SmartPLS the full collinearity test by connecting all the latent variables to one variable (Kock, 2015). The results show that the VIF values are lower than the tolerated threshold of 3.3 at the factor level (ranging from 1.01 to 2.62), which indicates that multicollinearity is not an issue.

\subsubsection{Second-Order Construction}

We performed specific tests to evaluate the second-order constructs. Formative constructs are measured by the collinearity between the indicators and the significance and the relevance of the external weights 
Table 5. AVE and correlation between latent variables

\begin{tabular}{|c|c|c|c|c|c|c|c|c|c|c|c|}
\hline & 1 & 2 & 3 & 4 & 5 & 6 & 7 & 8 & 9 & 10 & 11 \\
\hline 1.Trust Ability & 0.82 & & & & & & & & & & \\
\hline 2.Trust Benevolence & 0.44 & 0.93 & & & & & & & & & \\
\hline 3.Ease of Use & 0.25 & 0.16 & 0.84 & & & & & & & & \\
\hline $\begin{array}{l}\text { 4.Behaviour } \\
\text { Intention }\end{array}$ & 0.33 & 0.05 & 0.18 & 0.93 & & & & & & & \\
\hline 5.Trust Integrity & 0.70 & 0.6 & 0.26 & 0.23 & 0.85 & & & & & & \\
\hline 6.Social Norms & 0.40 & 0.30 & 0.05 & 0.38 & 0.43 & 0.75 & & & & & \\
\hline 7.Physical Risks & -0.13 & -0.02 & -0.15 & -0.17 & -0.08 & 0.20 & 0.86 & & & & \\
\hline 8.Private Risks & -0.03 & 0.08 & -0.08 & -0.21 & -0.08 & 0.12 & 0.40 & 0.92 & & & \\
\hline 9.Performance Risks & 0.08 & 0.13 & 0.03 & -0.02 & -0.06 & 0.13 & 0.27 & 0.38 & 0.73 & & \\
\hline 10.Supprt to Health & 0.50 & 0.36 & 0.18 & 0.42 & 0.36 & 0.45 & 0.04 & 0.06 & 0.13 & 0.80 & \\
\hline 11.Ubiqity & 0.33 & 0.22 & 0.61 & 0.32 & 0.31 & 0.17 & -0.15 & -0.11 & 0.03 & 0.33 & 0.84 \\
\hline
\end{tabular}

(Hair et al., 2016). Contrary to reflexive constructs, it is not possible to directly suppress a manifest variable that would have low validity since it would require a theoretical justification.

In the first step, the collinearity between the indicators must be checked; that is, the correlation between the indicators. To assess the level of collinearity, Hair et al. (2016) recommend calculating the level of variance of the formative indicator that is not explained by the other indicators. On SmartPLS, this calculation is performed by the variance inflation factor (VIF). Table 6 shows the VIF results for the second-level formative indicators. A value greater than 5 indicates a collinearity problem (Hair et al., 2011), meaning that $80 \%$ of the variance is associated with the other indicators that comprise the formative construct.

The second step is the evaluation of the weight of each indicator. The weight expresses the contribution relation of the indicator to the construct. The question that then arises is to know whether the indicator actually contributes to defining the formative construct. This contribution can be relative or absolute. The absolute contribution, that is, the impact of the indicator on the construct without taking into account the other indicators, is given by the load. When a weight is not significant, but

Table 6. Collinearity factor between indicators

\begin{tabular}{|l|l|l|}
\hline \multicolumn{1}{|c|}{ Second Order } & \multicolumn{1}{|c|}{ First Order } & \multicolumn{1}{c|}{ VIF } \\
\hline \multirow{4}{*}{ Trust } & Ability & 1,938 \\
\cline { 2 - 3 } & Integrity & 2,616 \\
\cline { 2 - 3 } & Benevolence & 1,680 \\
\hline \multirow{5}{*}{ Benefits } & Ease Of Use & 1,587 \\
\cline { 2 - 3 } & Social Norms & 1,256 \\
\cline { 2 - 3 } & Support To Health & 1,361 \\
\cline { 2 - 3 } & Ubiquity & 1,715 \\
\hline \multirow{5}{*}{ Risks } & Physical Risks & 1,212 \\
\cline { 2 - 3 } & Private Risks & 1,312 \\
\cline { 2 - 3 } & Performance Risks & 1,194 \\
\hline
\end{tabular}


Table 7. Weight and load of the indicators

\begin{tabular}{|l|l|l|l|l|l|l|l|}
\hline \multirow{4}{*}{ Second Order } & \multicolumn{1}{|c|}{ First Order } & Weight & Loading & $\begin{array}{c}\text { Weight T } \\
\text { Stat. }\end{array}$ & $\begin{array}{c}\text { Loading T } \\
\text { Stat. }\end{array}$ & $\begin{array}{c}\text { Significant } \\
\text { weight }\end{array}$ & $\begin{array}{c}\text { Significant } \\
\text { Loading }\end{array}$ \\
\hline \multirow{4}{*}{ Trust } & Ability & 0,804 & 0,982 & 5,407 & 29,824 & Yes & Yes \\
\cline { 2 - 8 } & Benevolence & 0,060 & 0,555 & 0,294 & 4,168 & No & Yes \\
\cline { 2 - 8 } & Integrity & 0,217 & 0,815 & 0,872 & 8,788 & No & Yes \\
\hline \multirow{5}{*}{ Benefits } & Ease Of Use & 0,118 & 0,412 & 1,137 & 4,205 & No & Yes \\
\cline { 2 - 8 } & Social Norms & 0,457 & 0,744 & 4,905 & 11,236 & Yes & Yes \\
\cline { 2 - 8 } & Support To Health & 0,519 & 0,840 & 4,496 & 13,889 & Yes & Yes \\
\cline { 2 - 8 } & Ubiquity & 0,288 & 0,606 & 2,994 & 7,530 & Yes & Yes \\
\hline \multirow{5}{*}{ Risks } & Physical Risks & 0,632 & 0,769 & 1,571 & 2,378 & No & Yes \\
\cline { 2 - 8 } & Private Risks & 0,667 & 0,740 & 1,913 & 2,574 & No & Yes \\
\cline { 2 - 8 } & Performance Risks & $-0,469$ & $-0,042$ & 1,074 & 0,118 & No & No \\
\hline
\end{tabular}

the load is significant $(>0.5)$, the indicator is absolute. Table 7 shows that performance risk does not contribute to expressing risk.

\subsection{Validity of The Structural Model}

Once the validity of the scales was verified, we tested the validity of the internal model. According to Hair et al. (2016), we should ensure that no correlation exists between the constructs; that is, they all represent different concepts. Accordingly (as with the formative constructs), we tested the variance inflation factor (VIF). Table 8 presents the results. All VIFs are less than 5 and validate the independence of the construct. Moreover, with the VIFs being lower than 3.3, the model is free of common methodological bias (Kock, 2015).

\subsubsection{Direct Effects}

This section focuses on the relationships between the different latent variables and thus test the validity of the hypotheses. Table 9 presents path coefficients. As the results show, only benefit (B $=0.512)$ and risk $(B=-0.232)$ have an influence on the intention to use STT. Trust influences the perception of benefit $(\mathrm{B}=0.589)$ but has no significant impact on the perception of risk and the intention to use STT.

Age, gender, occupation, and skill level in the use of self-monitoring devices were included as control variables. Their potential effects on intention to use STT was tested. Both age $(B=0.201)$ and skill $(B=0.118)$ influence intention. Gender does not influence behavioral intentions. Similarly, Baudier et al. (2020) found no empirical evidence when testing the moderating role of gender on the relationships between perceptions and attitude towards using smartwatch. Finally, the model yields an $\mathrm{R}^{2}=0.36$ for intention to use, an $\mathrm{R}^{2}=0.35$ for benefit, and an $\mathrm{R}^{2}=0.01$ for risk (see Figure 4 ).

Table 8. Collinearity factor of the structural model

\begin{tabular}{|l|l|l|l|l|}
\hline & \multicolumn{1}{|c|}{ Benefits } & \multicolumn{1}{c|}{ Trust } & \multicolumn{1}{c|}{ Behaviour Intention } & Risks \\
\hline Benefits & & & 1,580 & \\
\hline Trust & 1 & & 1,598 & 1 \\
\hline Risks & & & 1,093 & \\
\hline
\end{tabular}


Table 9. Summary of Path Coefficients and Reliability Levels

\begin{tabular}{|l|l|l|l|}
\hline \multicolumn{1}{|c|}{ Link } & \multicolumn{1}{c|}{ Path } & \multicolumn{1}{c|}{ T Statistics } & \multicolumn{1}{c|}{ Hypothesis } \\
\hline Hypothesis & & & \\
\hline Benefits -> Behaviour Intention & 0.512 & 6.417 & Confirmed \\
\hline Risks -> Behaviour Intention & -0.232 & 2.4 & Confirmed \\
\hline Trust -> Behaviour Intention & -0.054 & 0.574 & Not Confirmed \\
\hline Trust -> Benefits & 0.589 & 11.401 & Confirmed \\
\hline Trust -> Risks & -0.130 & 0.946 & Not Confirmed \\
\hline Control Variables & & & \\
\hline Age -> Behaviour Intention & 0.201 & 2.753 & Influence \\
\hline Competence -> Behaviour Intention & 0.118 & 2.193 & Influence \\
\hline Gender -> Behaviour Intention & 0.004 & 0.078 & Does not Influence \\
\hline Profession -> Behaviour Intention & 0.126 & 1.762 & Does not Influence \\
\hline
\end{tabular}

\subsubsection{Indirect Effects}

In addition to the calculation of direct effects, the authors checked the existence of benefit-risk mediating effects on the relationship between confidence and the intention to use STT. At the theoretical level, this means that an individual may have full confidence in the manufacturer, but this does not translate into an intention to use its product. In other situations, low confidence leads to high intention to use. The results presented in Table 10 show the indirect effects of trust on the intention to use mediated by risks and benefits.

From Table 10, it can be concluded that benefit plays a full mediating role between trust and intention to use.

Table 10. Indirect effects of trust on intent to use

\begin{tabular}{|l|l|l|l|}
\hline & \multicolumn{1}{|c|}{ Path } & \multicolumn{1}{c|}{ T Statistics } & \multicolumn{1}{c|}{ Confirmed } \\
\hline Trust $->$ Benefits $->$ Behaviour Intention & 0,302 & 5,084 & Yes \\
\hline Trust $->$ Risks $->$ Behaviour Intention & 0,030 & 1,244 & No \\
\hline
\end{tabular}

\subsection{The Effect of Unobservable Heterogeneous Groups}

The authors performed a final test to assess unobservable heterogeneity. This test is still absent in existing IS studies (Becker et al., 2013; Fosso Wamba et al., 2017). Its application allows interesting conclusions to be drawn and avoids interpretation bias (Becker et al., 2013). The authors used the REBUS-PLS algorithm (Esposito Vinzi et al., 2008) implemented in XLSTAT-PLS version 2019.1.1 to detect the groups. They tested the reflexive version of the model since the algorithm only works in this mode. The execution of the algorithm allowed us to detect three groups of 88,65 , and 83 individuals, which is put back into the SmartPLS software to evaluate the three models. The results are presented in Table 11.

Table 12 shows the different $\mathrm{R}^{2}$ values for each group. Class 1 and Class 3 validate four of the five hypotheses, but Class 3 leads to a much higher explained variance. 




\subsection{Identification of Class 3}

The authors cross-tabulated the different descriptive values of the study to identify the characteristics of individuals belonging to Class 3 . They performed a chi-square test to verify the hypothesis that this class demonstrates the different characteristics.

They also performed a chi-square test between the class variable and each of the other variables taken separately and found a link between the class and the use of technologies. The question asked was as follows: "Have you ever used a self-monitoring device to monitor your health?" The "yes" answer is related to Class 1, while the "no" answer is more related to Class 3.

The authors segmented age into three classes: $0-25,26-40$, and $>40$ and found a link with the classes. Class 1 is more related to the second age class, Class 2 is more related to the first age class, and Class 3 is more related to the third age class.

\section{DISCUSSION}

Three assumptions are validated. The ambivalence of risk versus benefit is verified. As a result, the model confirms that intention to use STT is influenced by both positive and negative user perceptions of STT (Kim et al., 2009; Mou \& Cohen, 2014; Yang et al., 2016). However, the influence of benefits is much more important than the influence of risks. The same finding was reported by Yang et al. (2016) in their study on the intention to use wearables through a model of benefit versus risk 
Table 11. Comparison of unobservable heterogeneous groups

\begin{tabular}{|c|c|c|c|c|c|c|c|c|c|}
\hline & \multicolumn{3}{|c|}{ Class 1} & \multicolumn{3}{|c|}{ Class 2} & \multicolumn{3}{|c|}{ Class 3} \\
\hline Link & Path & $\begin{array}{l}\text { T } \\
\text { Stat }\end{array}$ & Hypothesis & Path & T Stat & Hypothesis & Path & T Stat & Hypothesis \\
\hline \multicolumn{10}{|l|}{ Hypothesis } \\
\hline $\begin{array}{l}\text { Benefits -> } \\
\text { Behaviour } \\
\text { Intention }\end{array}$ & 0,513 & 3,378 & Confirmed & 0,498 & 2,505 & Confirmed & 0,565 & 5,265 & Confirmed \\
\hline $\begin{array}{l}\text { Risks -> } \\
\text { Behaviour } \\
\text { Intention }\end{array}$ & $-0,413$ & 2,547 & Confirmed & 0,481 & 2,043 & $\begin{array}{l}\text { Not } \\
\text { Confirmed }\end{array}$ & $-0,282$ & 2,408 & Confirmed \\
\hline $\begin{array}{l}\text { Trust -> } \\
\text { Behaviour } \\
\text { Intention }\end{array}$ & $-0,182$ & 0,944 & $\begin{array}{l}\text { Not } \\
\text { Confirmed }\end{array}$ & $-0,522$ & 2,169 & $\begin{array}{l}\text { Not } \\
\text { Confirmed }\end{array}$ & $-0,179$ & 1,484 & $\begin{array}{l}\text { Not } \\
\text { Confirmed }\end{array}$ \\
\hline $\begin{array}{l}\text { Trust -> } \\
\text { Benefits }\end{array}$ & 0,513 & 3,909 & Confirmed & 0,701 & 7,682 & Confirmed & 0,704 & 12,324 & Confirmed \\
\hline Trust $->$ Risks & $-0,437$ & 2,526 & Confirmed & 0,776 & 15,167 & $\begin{array}{l}\text { Not } \\
\text { Confirmed }\end{array}$ & $-0,563$ & 6,808 & Confirmed \\
\hline \multicolumn{10}{|l|}{$\begin{array}{l}\text { Control } \\
\text { Variable }\end{array}$} \\
\hline $\begin{array}{l}\text { Age -> } \\
\text { Behaviour } \\
\text { Intention }\end{array}$ & 0,089 & 0,693 & No effect & $-0,008$ & 0,078 & No effect & 0,256 & 2,174 & $\begin{array}{l}\text { Positive } \\
\text { effect }\end{array}$ \\
\hline $\begin{array}{l}\text { Competence } \\
->\text { Behaviour } \\
\text { Intention }\end{array}$ & 0,085 & 0,859 & No effect & 0,015 & 0,117 & No effect & 0,129 & 1,362 & No effect \\
\hline $\begin{array}{l}\text { Gender -> } \\
\text { Behaviour } \\
\text { Intention }\end{array}$ & 0,083 & 0,904 & No effect & $-0,079$ & 0,668 & No effect & 0,036 & 0,467 & No effect \\
\hline $\begin{array}{l}\text { Profession } \\
->\text { Behaviour } \\
\text { Intention }\end{array}$ & 0,0473 & 0,344 & No effect & $-0,060$ & 0,531 & No effect & 0,126 & 1,256 & No effect \\
\hline
\end{tabular}

Table 12. $\mathbf{R}^{2}$ for each class

\begin{tabular}{|l|l|l|l|}
\hline & \multicolumn{1}{|c|}{$\mathbf{R}^{2}$ class $\mathbf{1}$} & \multicolumn{1}{|c|}{$\mathbf{R}^{2}$ class 2 } & \multicolumn{1}{c|}{$\mathbf{R}^{2}$ class $\mathbf{3}$} \\
\hline Benefits & 0,26 & 0,49 & 0,50 \\
\hline Behaviour Intention & 0,37 & 0,36 & 0,56 \\
\hline Risks & $\mathbf{0 , 1 9}$ & $\mathbf{0 , 6 0}$ & $\mathbf{0 , 3 2}$ \\
\hline
\end{tabular}

assessment. According to the authors, this result can be explained by the fact that individuals already have experience with innovative mobile devices, such as smartphones. As such, they feel comfortable with these products and are therefore accustomed to their risks. According to Rogers (1962), new adopters are the ones who are willing to take more risks to test the technology.

Among the perceived benefits, health support carries significant weight. This shows that mentalities are changing and that monitoring tools are no longer perceived as gadgets. According to a survey conducted for Unicancer (Ticsante, 2017), the French are making progress in their perception 
Table 13. Contingent table between classes and usage

\begin{tabular}{|l|l|l|l|l|}
\hline & \multicolumn{2}{|c|}{ Usage } & \multicolumn{2}{c|}{ Residual } \\
\hline & Already used & Never Used & Already used & Never Used \\
\hline Class \#1 & 54 & 34 & 3.78 & -2.89 \\
\hline Class \#2 & 15 & 50 & -1.83 & 1.39 \\
\hline Class \#3 & 18 & 65 & -2.27 & 1.74 \\
\hline
\end{tabular}

of connected health. They are more likely to view it as an opportunity to improve care (76\% in 2017 versus 67\% in 2015) and to prevent disease (82\% in 2017 versus 78\% in 2015) (Ticsante, 2017). The perception of a mature technology capable of assisting the individual in managing one's health is reinforced by the low weight of performance as a risk. While research has identified measurement variations among different products on the market (An et al., 2017; Gruwez et al., 2017; Lee et al., 2017; Price et al., 2017), individuals do not appear to be sensitive to the reliability of the tool. Another hypothesis would be that potential users do not expect to have a tool that does not work satisfactorily. Similarly, ease of use bears little weight on perceived benefit. The same finding is reported in a study of fitness tools (Lunney et al., 2016). This would be explained by the fact that users have now acquired sufficient experience and skill with the technology (Wang et al., 2014). In addition, half of the sample consists of digital natives who are much more comfortable with new technologies (Vodanovich et al., 2010): These individuals have an aptitude for learning new technologies and use them in a very natural way.

Social norms also play an important role in perceived benefits. Connected watches and fitness trackers are often gifts from people who care about the recipients' health and wellbeing. In communities, such as runners, an athlete tends to imitate others in order to fit in. If all runners have connected watches to keep track of their heart rates, the individual tends to buy a similar connected watch to be able to compare oneself to others.

Concerning the risks, the physical injury caused to the individual by the tool is perceived to be a major risk, as well as the risk of the violation of privacy. Gurtner (2014) points out a similar result of his study on mobile health apps, where he cites the example of medical information and recommendations delivered by the app that can lead the individual to act against one's health. There is also the risk of the wearable object itself, in direct contact with the individual's body. The results confirm the research interest in addressing privacy issues.

As opposed to other studies that have used the extended valence model, trust has no influence on the intention to use STT. The impact of this factor has been validated several times in the use of self-monitoring tools (Gao et al., 2016; Pfeiffer et al., 2016). However, confidence can have several different constructions. In the study by Gao et al. (2016), it refers to the reliability of measurements and a certain quality (Gefen et al., 2003). For Pfeiffer et al. (2016), it consists of vendor reliability,

Table 14. Contingent table between age and usage

\begin{tabular}{|l|l|l|l|l|l|l|}
\hline & \multicolumn{2}{|c|}{ Age } & & \multicolumn{2}{c|}{ Residual } & $\mathbf{2 6 - 4 0}$ \\
\hline & $\mathbf{0 - 2 5}$ & $\mathbf{2 6 - 4 0}$ & $\mathbf{7 4 0}$ & $\mathbf{0 - 2 5}$ & $\mathbf{2 0}$ & $\mathbf{4 0}$ \\
\hline Class \#1 & 37 & 26 & 25 & -1.35 & 2.73 & -0.28 \\
\hline Class \#2 & 48 & 5 & 12 & 2.36 & -1.87 & -1.70 \\
\hline Class \#3 & 39 & 10 & 34 & -0.69 & -1.16 & 1.80 \\
\hline
\end{tabular}


data storage security, and invasion of privacy. In this study, trust is based on the manufacturer's benevolence, ability, and integrity, as in the model of e-health adoption (Mou et al., 2016).

Although trust does not play a direct role in intention to use, the results show that benefit mediates this relationship. It is only through benefit that trust increases intention to use. Among the dimensions of trust, ability plays an important role. The indicators that comprise this construct emphasize the tool provider's ability to help the individual manage one's health; thus, ability is akin to health support (see Appendix E for the direct and the indirect effects of ability on the dimensions of benefit). The perception of the provider's skill increases the perceived benefit in managing an individual's health and therefore increases the intent to use. Integrity plays a direct role in performance risks. The more the provider is perceived as having integrity and being able to provide quality data, the more the performance risk is mitigated (see Appendix E).

Finally, age and skills (control variables) influence intention to use.

\section{IMPLICATIONS}

\subsection{Theoretical Implications}

This research contributes in several ways to IS research and more precisely to the sub-stream of IS adoption. First, while prior research on IS adoption has mainly applied the TAM (Davis 1989) as noted by Lee et al. (2003), we encourage IS researchers to explore more relevant models to study STT. Indeed, the TAM seems to offer a limited contribution to the examination of STT adoption because ease of use (a key variable of TAM) tends to be inherent of STT since only 5\% of the respondents consider a self-monitoring tool difficult to use. Actually, ease of use of emerging technologies (e.g. sensors or chatbots) may indeed gradually lose its relevance in favor of other variables, such as interactivity and quality of communication with the tool (Vodanovich et al., 2010; Go and Sundar, 2019). Go and Sundar (2019) showed that anthropomorphism, message interactivity and identity cues tend be expected from users of chatbots. Vodanovich et al. (2010) also noticed that the joint development of digital natives, people who have grown up in a digital world, and ubiquitous technologies require a paradigm shift. This study confirms the suitability of the Extended Valence Framework to examine STT adoption. This model has already been used in e-commerce (Kim et al., 2009) and e-health services (Mou et al., 2016) contexts, but not yet in STT context. Therefore, we encourage IS researchers to continue extending the Valence Framework. More recently, Turel et al. (2020, p.1) also pointed out the rise of a digitized self, defined as "users who use at least one digital technology in their non-work life domains", which requires a socio-technical perspective. These different calls should invite IS researchers to diversify their theoretical backgrounds to study STT.

Second, the risk/benefit model is based on the technical, social, and medical dimensions of STT that have been repeated throughout the literature on self-quantification; as such, it enriches previous conceptualizations. We have identified the various perceived risks and benefits that influence STT adoption. The findings indicate that social norms and privacy are important predictors of intentions to use. This finding supports prior research (De Moya and Pallud, 2020, Kang \& Jung, 2020). For instance, De Moya and Pallud (2020) showed that anonymous surveillance enabled by STT represents a source of disempowerment for users and a real concern that can influence continued usage. Surprisingly, the technical dimension, which is highly present in the literature, does not emerge as fundamental in this study. The analysis enables a critical reflection on the factors to be considered when designing STT tools and could inspire academics conducting Design Science Research (Hevner et al. 2004).

\subsection{Managerial Contributions}

This research has several management implications. The prevalence of health factors and potential threats to the body and privacy should guide manufacturers in adopting new product development strategies. In the near future, we should witness the emergence of standards that are closer to medical 
standards so that these tools would finally shift away from gadgets and become aids to diagnosis and medical monitoring. This data accuracy will need to be complemented by clear security and privacy policies. Closeness with the medical world should be boosted by the emergence of medical data storage systems. For example, since 2018, the French postal service has offered a new health application that facilitates the sharing of personal health data (such as ST) with the medical profession. Recently, Fitbit inc. launched a study conducted with the users of its wearables to contribute to the early detection of COVID-19 and the flu (Etherington, 2020).

Thus, in the medium term, there should be a convergence of medical and ST data. Manufacturers should then work more on storage solutions that are secure yet open enough to allow exchange with other applications. We advise designers to take this aspect into consideration and vendors to communicate their ability to maintain user security and privacy. For instance, Apple does it for its health app that stores Apple Watch data (Apple, 2018), as can be read on their website (www.apple.com/ios/health/).

Furthermore, with COVID-19, several countries such as Singapore, South Korea, and France have developed and sometimes enforce the usage of a mobile application to encourage citizens to signal any early symptoms. However, Rowe et al. (2020) examined the French Stop-COVID app and showed that the coercive communication adopted by the French government to promote the app generated distrust and low adoption rates. Actually, the alienating context and the flawed design of the app contributed to its low deployment. Thus, Rowe et al. (2020) insist on the importance of collaboration across disciplines and fields of expertise to design less alienating apps. The design of STT also requires collaborative teams of experts and scientists to better acknowledge the impacts of these technologies on people's life and to reduce their potential risks.

\section{LIMITATIONS AND CONCLUSIONS}

Despite all the care and attention paid in that study, it reveals certain limitations. First, the questionnaire consists of a large number of constructions, which makes it time-consuming to complete. As a result, the authors have been confronted with a high dropout rate. The sample is therefore limited to 236 respondents. The presence of different classes in the sample represents another limitation because it can to lead to significant variations in the results.

The second limitation concerns formative constructs. The analysis shows that performance risk is only marginally involved in risk formation. Additionally, although a model comprising second-order constructs is more elegant and avoids many links, it also hides certain relationships, as shown in the table in Appendices $\mathrm{G}$ and $\mathrm{H}$.

Taking over existing constructs to adapt them to a specific context is also a limitation. Indeed, the questions may seem too generalist, as is the case for performance risk and trust.

Finally, we believe that it would be more effective to introduce the tool through demonstrations in order to allow the layperson to try out the system for a few days. In that way, an individual can identify the usefulness of the tool and its dangers, thereby reducing the inequalities in risks between those who are knowledgeable and those who lack knowledge (Cooper, 2008).

In conclusion, this paper proposes a new model for assessing the intention to use ST tools. The results show that the individual performs a benefit-versus-risk calculation. However, the risks that we have identified seem to be much less important in relation to the benefits that the tool can bring in terms of health and social image. That study is the first to show that health support is an important factor in selfmonitoring tools. Furthermore, it indicates that trust plays a role in perceived benefits and has an indirect influence on the intention to use ST tools. Finally, the research suggests that self-monitoring tools should be approached from a perspective that is close to medical standards in order to provide important benefits in managing an individual's health. 


\section{REFERENCES}

Adibi, S. (2015). Mobile Health—A Technology Road Map. Springer International Publishing. www.springer. com/fr/book/9783319128160

Ajani, T. (2014). Exploring the Implications of Technology Acceptance Models for Sensor-based Global Health Technologies. Proceedings of the Information Systems Educators Conference. http://citeseerx.ist.psu.edu/viewdoc/ download?doi=10.1.1.688.5516\&rep=rep1\&type $=$ pdf

Ajzen, I. (1991). The theory of planned behavior. Organizational Behavior and Human Decision Processes, 50(2), 179-211. doi:10.1016/0749-5978(91)90020-T

Alley, S., Jennings, C., Duncan, M., Schoeppe, S., Gurtler, D., \& Vandelanotte, C. (2016). Attitudes, intentions and preferences for using physical activity tracking devices. BMJ Open, 6. doi:10.1136/bmjopen-2016-011243

Almalki, M., Sanchez, F. M., \& Gray, K. (2015). Quantifying the Activities of Self-quantifiers: Management of Data, Time and Health. Studies in Health Technology and Informatics, 216, 333-337. PMID:26262066

Altenhoff, B., Vaigneur, H., \& Caine, K. (2015). One step forward, two steps back: The key to wearables in the field is the app. Pervasive Computing Technologies for Healthcare (PervasiveHealth), 2015 9th International Conference on, 241-244. https://ieeexplore.ieee.org/xpls/abs_all.jsp?arnumber=7349407

An, H.-S., Jones, G. C., Kang, S.-K., Welk, G. J., \& Lee, J.-M. (2017). How valid are wearable physical activity trackers for measuring steps? European Journal of Sport Science, 17(3), 360-368. doi:10.1080/17461391.201 6.1255261 PMID:27912681

Anderson, C. L., \& Agarwal, R. (2011). The Digitization of Healthcare: Boundary Risks, Emotion, and Consumer Willingness to Disclose Personal Health Information. Information Systems Research, 22(3), 469-490. doi: $10.1287 /$ isre. 1100.0335

Ayanso, A., Herath, T. C., \& O'Brien, N. (2015). Understanding continuance intentions of physicians with electronic medical records (EMR): An expectancy-confirmation perspective. Decision Support Systems, 77, 112-122. doi:10.1016/j.dss.2015.06.003

Aytes, K., \& Connolly, T. (2004). Computer security and risky computing practices: A rational choice perspective. Journal of Organizational and End User Computing, 16(3), 22-40. doi:10.4018/joeuc.2004070102

Bandura, A. (1986). Social foundations of thought and action. Academic Press.

Barth, J. (2013). The Human Cloud: Wearable Technology from Novelty to Production. Rackspace: The Open Cloud Company. http://research.gold.ac.uk/id/eprint/15056

Baudier, P., Ammi, C., \& Wamba, S. F. (2020). Differing perceptions of the Smartwatch by users within developed countries. Journal of Global Information Management, 28(4), 1-20. doi:10.4018/JGIM.2020100101

Bauer, R. (1967). Consumer Behavior as Risk Taking. In Risk Taking and Information Handling in Consumer Behavior. Harvard University.

Beck, U. (1992). Risk society: Towards a new modernity (Vol. 17). Sage.

Becker, J.-M., Klein, K., \& Wetzels, M. (2012). Hierarchical Latent Variable Models in PLS-SEM: Guidelines for Using Reflective-Formative Type Models. Long Range Planning, 45(5), 359-394. doi:10.1016/j.lrp.2012.10.001

Becker, J.-M., Rai, A., Ringle, C. M., \& Völckner, F. (2013). Discovering unobserved heterogeneity in structural equation models to avert validity threats. Management Information Systems Quarterly, 37(3), 665-694. doi:10.25300/MISQ/2013/37.3.01

Becker, M., Kolbeck, A., Matt, C., \& Hess, T. (2017a). Understanding the Continuous Use of Fitness Trackers: A Thematic Analysis. Academic Press.

Becker, M., Matt, C., Widjaja, T., \& Hess, T. (2017b). Understanding Privacy Risk Perceptions of Consumer Health Wearables-An Empirical Taxonomy. Academic Press.

Bergmann, J. H. M., \& McGregor, A. H. (2011). Body-worn sensor design: What do patients and clinicians want? Annals of Biomedical Engineering, 39(9), 2299-2312. doi:10.1007/s10439-011-0339-9 PMID:21674260 
Biernacki, P., \& Waldorf, D. (1981). Snowball sampling: Problems and techniques of chain referral sampling. Sociological Methods \& Research, 10(2), 141-163. doi:10.1177/004912418101000205

Buchwald, A., Letner, A., Urbach, N., \& von Entress-Fuersteneck, M. (2015). Towards Explaining the Use of Self-Tracking Devices: Conceptual Development of a Continuance and Discontinuance Model. Proceedings of the 36th International Conference on Information Systems. https://aisel.aisnet.org/icis2015/proceedings/ ITimplementation/24/

Buenaflor, C., \& Kim, H.-C. (2012). Wearable computers in human perspective: The decision process of innovation acceptance with user issues and concerns. International Journal of Emerging Technology and Advanced Engineering, 2(11), 573-580.

Bulgurcu, B., Cavusoglu, H., \& Benbasat, I. (2010). Information security policy compliance: An empirical study of rationality-based beliefs and information security awareness. Management Information Systems Quarterly, 34(3), 523-548. doi:10.2307/25750690

Canhoto, A. I., \& Arp, S. (2017). Exploring the factors that support adoption and sustained use of health and fitness wearables. Journal of Marketing Management, 33(1/2), 32-60. doi:10.1080/0267257X.2016.1234505

Carter, E. (2013). Marketing "smart" medical innovation: Physicians' attitudes and intentions. International Journal of Pharmaceutical and Healthcare Marketing, 2(4), 307-320. doi:10.1108/17506120810922349

Chan, M., Estève, D., Fourniols, J.-Y., Escriba, C., \& Campo, E. (2012). Smart wearable systems: Current status and future challenges. Artificial Intelligence in Medicine, 56(3), 137-156. doi:10.1016/j.artmed.2012.09.003 PMID:23122689

Chen, C.-C., \& Shih, H.-S. (2014). A study of the acceptance of wearable technology for consumers-An ANP perspective. International Journal of the Analytic Hierarchy Process. http://tkuir.lib.tku.edu.tw/dspace/ handle/987654321/100425

Cheng, J. W., \& Mitomo, H. (2017). The underlying factors of the perceived usefulness of using smart wearable devices for disaster applications. Telematics and Informatics, 34(2), 528-539. doi:10.1016/j.tele.2016.09.010

Cho, J., Lee, H. E., Kim, S. J., \& Park, D. (2015). Effects of body image on college students' attitudes toward diet/fitness apps on smartphones. Cyberpsychology, Behavior, and Social Networking, 18(1), 41-45. doi:10.1089/ cyber.2014.0383 PMID:25584729

Choi, J., \& Kim, S. (2016). Is the smartwatch an IT product or a fashion product? A study on factors affecting the intention to use smartwatches. Computers in Human Behavior, 63, 777-786. doi:10.1016/j.chb.2016.06.007

Chuah, S. H.-W., Rauschnabel, P. A., Krey, N., Nguyen, B., Ramayah, T., \& Lade, S. (2016). Wearable technologies: The role of usefulness and visibility in smartwatch adoption. Computers in Human Behavior, 65, 276-284. doi:10.1016/j.chb.2016.07.047

Ciborra, C. (2004). Digital Technologies and the Duality of Risk. Academic Press.

Cocosila, M., Archer, N., \& Yuan, Y. (2009). Early investigation of new information technology acceptance: A perceived risk-motivation model. Communications of the Association for Information Systems, 25(1), 30. doi:10.17705/1CAIS.02530

Cooper, M. (2008). The inequality of security: Winners and losers in the risk society. Human Relations, 61(9), 1229-1258. doi:10.1177/0018726708094911

Crawford, K., Lingel, J., \& Karppi, T. (2015). Our metrics, ourselves: A hundred years of self-tracking from the weight scale to the wrist wearable device. European Journal of Cultural Studies, 18(4-5), 479-496. doi: $10.1177 / 1367549415584857$

Davis, F. D. (1989). Perceived usefulness, perceived ease of use, and user acceptance of information technology. Management Information Systems Quarterly, 13(3), 319-340. doi:10.2307/249008

De Moya, J.-F., \& Pallud, J. (2017). Quantified-self: A literature review based on the funnel paradigm. ECIS. https://aisel.aisnet.org/ecis2017_rp/108/

De Moya, J.-F., \& Pallud, J. (2020). From panopticon to heautopticon : A new form of surveillance introduced by quantified-self practices. Information Systems Journal. 10.1111/isj.12284 
Dehghani, M. (2016). An assessment towards adoption and diffusion of smart wearable technologies by consumers: The cases of smart watch and fitness wristband products. 27th ACM Conference on Hypertext and Social Media. http://ceur-ws.org/Vol-1628/DC_2.pdf

del Río Carral, M., Roux, P., Bruchez, C., \& Santiago-Delefosse, M. (2017). Santé digitale: Promesses, défis et craintes. Une revue de la littérature. Pratiques Psychologiques, 23(1), 61-77. doi:10.1016/j.prps.2016.06.004

Deng, Z., Mo, X., \& Liu, S. (2014). Comparison of the middle-aged and older users' adoption of mobile health services in China. International Journal of Medical Informatics, 83(3), 210-224. doi:10.1016/j. ijmedinf.2013.12.002 PMID:24388129

Dewan, S., \& Ren, F. (2007). Risk and Return of Information Technology Initiatives: Evidence from Electronic Commerce Announcements. Information Systems Research, 18(4), 370-394. doi:10.1287/isre.1070.0120

Dinev, T., Bellotto, M., Hart, P., Russo, V., Serra, I., \& Colautti, C. (2006). Privacy calculus model in e-commerce-A study of Italy and the United States. European Journal of Information Systems, 15(4), 389-402. doi:10.1057/palgrave.ejis. 3000590

Dinev, T., \& Hart, P. (2006). An Extended Privacy Calculus Model for E-Commerce Transactions. Information Systems Research, 17(1), 61-80. doi:10.1287/isre.1060.0080

Doolin, B., Dillon, S., Thompson, F., \& Corner, J. L. (2005). Perceived risk, the Internet shopping experience and online purchasing behavior: A New Zealand perspective. Journal of Global Information Management, 13(2), 66-88. doi:10.4018/jgim.2005040104

Dredge, S. (2013, September 3). Yes, those free health apps are sharing your data with other companies. The Guardian. https://www.theguardian.com/technology/appsblog/2013/sep/03/fitness-health-apps-sharing-datainsurance

Driouchi, A., Wang, M., \& Driouchi, T. (2015). Determinants of software piracy under risk aversion: A model with empirical evidence. European Journal of Information Systems, 24(5), 519-530. doi:10.1057/ejis.2014.14

DuFour, A., Lajeunesse, K., Pipada, R., Xu, S., \& Nomee, J. (2017). The effect of data security perception on wearable device acceptance: A technology acceptance model. Proceedings of Student-Faculty Research Day, D11, 1-6.

Ehlers, D. K., \& Huberty, J. L. (2014). Middle-Aged Women's Preferred Theory-Based Features in Mobile Physical Activity Applications. Journal of Physical Activity \& Health, 11(7), 1379-1385. doi:10.1123/jpah.20120435 PMID:24368818

Esposito Vinzi, V., Trinchera, L., Squillacciotti, S., \& Tenenhaus, M. (2008). REBUS-PLS: A response-based procedure for detecting unit segments in PLS path modelling. Applied Stochastic Models in Business and Industry, 24(5), 439-458. doi:10.1002/asmb.728

Etherington, D. (2020). Fitbit launches a COVID-19 early detection study, and you can join from the Fitbit app. https://techcrunch.com/2020/05/21/fitbit-launches-a-covid-19-early-detection-study-and-you-can-joinfrom-the-fitbit-app/

Featherman, M. S., \& Pavlou, P. A. (2003). Predicting e-services adoption: A perceived risk facets perspective. International Journal of Human-Computer Studies, 59(4), 451-474. doi:10.1016/S1071-5819(03)00111-3

Fensli, R., \& Boisen, E. (2008). How to evaluate human factors affecting wireless biomedical sensorsIdentifying aspects of patient acceptance based on a preliminary clinical trial (L. Azevedo \& A. R. Londral, Eds.). Academic Press.

Fensli, R., Pedersen, P. E., Gundersen, T., \& Hejlesen, O. (2008). Sensor acceptance model-Measuring patient acceptance of wearable sensors. Methods of Information in Medicine, 47(1), 89-95. doi:10.3414/ME9106 PMID: 18213434

Fisher, R. J., \& Price, L. L. (1992). An investigation into the social context of early adoption behavior. The Journal of Consumer Research, 19(3), 477-486. doi:10.1086/209317

Fornell, C., \& Larcker, D. F. (1981). Evaluating Structural Equation Models with Unobservable Variables and Measurement Error. JMR, Journal of Marketing Research, 18(1), 39-50. doi:10.1177/002224378101800104 
Fosso Wamba, S., Bhattacharya, M., Trinchera, L., \& Ngai, E. W. T. (2017). Role of intrinsic and extrinsic factors in user social media acceptance within workspace: Assessing unobserved heterogeneity. International Journal of Information Management, 37(2), 1-13. doi:10.1016/j.ijinfomgt.2016.11.004

Fox, S., \& Duggan, M. (2013, January 28). Tracking for Health. Pew Research Center: Internet, Science \& Tech. https://www.pewinternet.org/2013/01/28/tracking-for-health/

Gao, S., Zhang, X., \& Peng, S. (2016). Understanding the Adoption of Smart Wearable Devices to Assist Healthcare in China. In Y. K. Dwivedi, M. Mantymaki, M. N. Ravishankar, M. Janssen, M. Clement, E. L. Slade, N. P. Rana, S. Alsharhan, \& A. C. Simintiras (Eds.), Social Media: The Good, the Bad, and the Ugly (Vol. 9844, pp. 280-291). Academic Press.

Gao, Y., Li, H., \& Luo, Y. (2015). An empirical study of wearable technology acceptance in healthcare. Industrial Management \& Data Systems, 115(9), 1704-1723. doi:10.1108/IMDS-03-2015-0087

Gay, V., \& Leijdekkers, P. (2011). The good, the bad and the ugly about social networks for health apps. Embedded and Ubiquitous Computing (EUC), 2011 IFIP 9th International Conference On, 463-468. https://ieeexplore. ieee.org/abstract/document/6104569/

Gefen, D. (2000). E-commerce: The role of familiarity and trust. Omega, 28(6), 725-737. doi:10.1016/S03050483(00)00021-9

Gefen, D., Karahanna, E., \& Straub, D. W. (2003). Trust and Tam in Online Shopping: An Integrated Model. Management Information Systems Quarterly, 27(1), 51-90. doi:10.2307/30036519

Gefen, D., \& Straub, D. (2005). A practical guide to factorial validity using PLS-Graph: Tutorial and annotated example. Communications of the Association for Information Systems, 16(1), 5. doi:10.17705/1CAIS.01605

Gefen, D., Straub, D., \& Boudreau, M.-C. (2000). Structural equation modeling and regression: Guidelines for research practice. Communications of the Association for Information Systems, 4(1), 7. doi:10.17705/1CAIS.00407

Gilbert, M., \& Namagembe, F. (2013). Understanding User Adoption of Mobile Health Technology in a Resource Constrained Environment. 2013 Pan African International Conference on Information Science, Computing and Telecommunications (PACT), 56-61. doi:10.1109/SCAT.2013.7055089

Gimhae, G.-N. (2013). Six human factors to acceptability of wearable computers. International Journal of Multimedia and Ubiquitous Engineering. http://www.sersc.org/journals/IJMUE/vol8_no3_2013/10.pdf

Gimpel, H., Nissen, M., \& Görlitz, R. (2013). Quantifying the quantified self: A study on the motivations of patients to track their own health. Thirty Fourth International Conference on Information Systems. https://aisel. aisnet.org/icis2013/proceedings/HealthcareIS/3/

Go, E., \& Sundar, S. S. (2019). Humanizing chatbots : The effects of visual, identity and conversational cues on humanness perceptions. Computers in Human Behavior, 97, 304-316. doi:10.1016/j.chb.2019.01.020

Granjon, F., Nikolski, V., \& Pharabod, A.-S. (2012). Métriques de soi et self-tracking: Une nouvelle culture de soi à l'ère du numérique et de la modernité réflexive? Recherches En Communication, 36(36), 13-26. doi:10.14428/rec.v36i36.50983

Greenfield, R., Busink, E., Wong, C. P., Riboli-Sasco, E., Greenfield, G., Majeed, A., Car, J., \& Wark, P. A. (2016). Truck drivers' perceptions on wearable devices and health promotion: A qualitative study. BMC Public Health, 16(1), 677. doi:10.1186/s12889-016-3323-3 PMID:27475984

Grewal, D., Gotlieb, J., \& Marmorstein, H. (1994). The moderating effects of message framing and source credibility on the price-perceived risk relationship. The Journal of Consumer Research, 21(1), 145-153. doi:10.1086/209388

Gribel, L., Regier, S., \& Stengel, I. (2016). Acceptance Factors of Wearable Computing: An Empirical Investigation. Proceedings of the Eleventh International Network Conference (INC 2016), 67. https://books. google.com/books?hl=en\&lr=\&id=hBqqDAAAQBAJ\&oi=fnd\&pg=PA67\&dq=\%22study+consisting + of $+\mathrm{e}$ xpert+interviews+and $\% 22+\% 22$ pervasiveness $\% 3 \mathrm{~B}+$ perceived+IT+security $\% 3 \mathrm{~B}+\mathrm{Big}+$ Five $\% 22+\% 22$ which +people+conceive,+experience+and+employ $\% 22+\% 22$ since $+\% \mathrm{E} 2 \% 80 \% 9 \mathrm{Cwearables} \% \mathrm{E} 2 \% 80 \% 9 \mathrm{D}+$ afford $+\mathrm{a}+$ continuous $\% 22+\% 22 \% 5 \mathrm{~B} 2 \% 5 \mathrm{D} .+\mathrm{In}+\mathrm{view}+\mathrm{of}+$ the + numerous + efforts $+\mathrm{in}+$ the + area $\% 22+\& o t s=1 \mathrm{cEFm}$ 9Jj95\&sig=qQYZSRXgJZbgZ-Oh4OskHaenKG4 
Gualtieri, L., Rosenbluth, S., \& Phillips, J. (2016). Can a Free Wearable Activity Tracker Change Behavior? The Impact of Trackers on Adults in a Physician-Led Wellness Group. Iproceedings, 2(1), e1. doi:10.2196/ iproc.6245 PMID:27903490

Guo, X., Sun, Y., Yan, Z., \& Wang, N. (2012). Privacy-Personalization Paradox in Adoption of Mobile Health Service: The Mediating Role of Trust. PACIS, 27. https://pdfs.semanticscholar.org/4871/70857a47d915b66c0 ede13eb836a2d5c91b3.pdf

Gurtner, S. (2014). Modelling consumer resistance to mobile health applications. ICIS 2014.

Hair, J., Hult, G. T. M., Ringle, C., \& Sarstedt, M. (2016). A Primer on Partial Least Squares Structural Equation Modeling (PLS-SEM). SAGE Publications.

Hair, J. F., Ringle, C. M., \& Sarstedt, M. (2011). PLS-SEM: Indeed a Silver Bullet. Journal of Marketing Theory and Practice, 19(2), 139-152. doi:10.2753/MTP1069-6679190202

Herrmann, L. K., \& Kim, J. (2017). The fitness of apps: A theory-based examination of mobile fitness app usage over 5 months. Health, 3, 2. Advance online publication. doi:10.21037/mhealth.2017.01.03 PMID:28293619

Hevner, A. R., \& Salvatore, T. (2004). March, Jinsoo Park and Sudha Ram, Design Science in Information Systems Research. Management Information Systems Quarterly, 28(1), 75-105. doi:10.2307/25148625

Hirose, M., \& Tabe, K. (2016). Responses to mhealth application on health behavior: A theoretical extension of the technology acceptance model. In C. Campbell \& J. J. Ma (Eds.), Looking Forward, Looking Back: Drawing on the Past to Shape the Future (pp. 46-55). doi:10.1007/978-3-319-24184-5_13

Hong, J.-C., Lin, P.-H., \& Hsieh, P.-C. (2017). The effect of consumer innovativeness on perceived value and continuance intention to use smartwatch. Computers in Human Behavior, 67, 264-272. doi:10.1016/j. chb.2016.11.001

Hong, W., \& Thong, L. (2013). Internet Privacy Concerns: An Integrated Conceptualization and Four Empirical Studies. Management Information Systems Quarterly, 37(1), 275-298. doi:10.25300/MISQ/2013/37.1.12

Horst, M., Kuttschreuter, M., \& Gutteling, J. M. (2007). Perceived usefulness, personal experiences, risk perception and trust as determinants of adoption of e-government services in The Netherlands. Computers in Human Behavior, 23(4), 1838-1852. doi:10.1016/j.chb.2005.11.003

Huang, F.-F., \& Lai, Y.-H. (2016). The Acceptance of Smart Wearable Devices through Health Cognitive. In C. H. Liu \& C. C. Wang (Eds.), International Conference on Computing and Precision Engineering (iccpe 2015) (Vol. 71, p. UNSP 05005). doi:10.1051/matecconf/20167105005

Huberty, J., Ehlers, D. K., Kurka, J., Ainsworth, B., \& Buman, M. (2015). Feasibility of three wearable sensors for 24 hour monitoring in middle-aged women. BMC Women's Health, 15(1), 55. doi:10.1186/s12905-0150212-3 PMID:26223521

Illiger, K., Hupka, M., von Jan, U., Wichelhaus, D., \& Albrecht, U.-V. (2014). Mobile Technologies: Expectancy, Usage, and Acceptance of Clinical Staff and Patients at a University Medical Center. JMIR mHealth and uHealth, 2(4), e42. doi:10.2196/mhealth.3799 PMID:25338094

Jacoby, J., \& Kaplan, L. B. (1972). The components of perceived risk. ACR.

Jeong, S. C., Kim, S.-H., Park, J. Y., \& Choi, B. (2017). Domain-specific innovativeness and new product adoption: A case of wearable devices. Telematics and Informatics, 34(5), 399-412. doi:10.1016/j.tele.2016.09.001

Jia, X., \& Kim, J. (2015). Development of a Conceptual Model to Understand the Adoption of Wearable Technology. International Textile and Apparel Association. https://lib.dr.iastate.edu/itaa_proceedings/2015/ posters/24/

Jiang, Y. (2015). Factors associated with acceptance and use of mobile technology for health self-monitoring and decision support in lung transplant recipients. University of Pittsburgh.

Joseph, N., Kar, A. K., Ilavarasan, P. V., \& Ganesh, S. (2017). Review of discussions on internet of things (IoT): Insights from twitter analytics. Journal of Global Information Management, 25(2), 38-51. doi:10.4018/ JGIM.2017040103 
Jung, Y., Kim, S., \& Choi, B. (2016). Consumer valuation of the wearables: The case of smartwatches. Computers in Human Behavior, 63, 899-905. doi:10.1016/j.chb.2016.06.040

Jusob, F. R., George, C., \& Mapp, G. (2016). Enforcing trust as a means to improve adoption of connected wearable technologies. 12th International Conference on Intelligent Environments - Ie 2016, 254-257. doi:10.1109/IE.2016.58

Kahneman, D., \& Tversky, A. (2013). Choices, values, and frames. In Handbook of the Fundamentals of Financial Decision Making: Part I (pp. 269-278). World Scientific. doi:10.1142/9789814417358_0016

Kang, H., \& Jung, E. H. (2020). The smart wearables-privacy paradox : A cluster analysis of smartwatch users. Behaviour \& Information Technology, 1-14. doi:10.1080/0144929X.2020.1778787

Kim, D. J., Ferrin, D. L., \& Rao, H. R. (2008). A trust-based consumer decision-making model in electronic commerce: The role of trust, perceived risk, and their antecedents. Decision Support Systems, 44(2), 544-564. doi:10.1016/j.dss.2007.07.001

Kim, D. J., Ferrin, D. L., \& Rao, H. R. (2009). Trust and Satisfaction, Two Stepping Stones for Successful E-Commerce Relationships: A Longitudinal Exploration. Information Systems Research, 20(2), 237-257. doi:10.1287/isre.1080.0188

Kim, K. J., \& Shin, D.-H. (2015). An acceptance model for smart watches. Internet Research, 25(4), 527-541. doi:10.1108/IntR-05-2014-0126

Kock, N. (2015). Common method bias in PLS-SEM: A full collinearity assessment approach. [IJeC]. International Journal of e-Collaboration, 11(4), 1-10. doi:10.4018/ijec.2015100101

Lebron, J., Escalante, K., Coppola, J., \& Gaur, C. (2015). Activity Tracker Technologies for Older Adults: Successful Adoption via Intergenerational Telehealth. 2015 Ieee Long Island Systems, Applications and Technology Conference (Lisat).

Lee, E., Han, S., \& Jo, S. H. (2017). Consumer choice of on-demand mHealth app services: Context and contents values using structural equation modeling. International Journal of Medical Informatics, 97, 229-238. doi:10.1016/j.jimedinf.2016.10.016 PMID:27919381

Lee, H.-A., Lee, H.-J., Moon, J.-H., Lee, T., Kim, M.-G., In, H., Cho, C.-H., \& Kim, L. (2017). Comparison of Wearable Activity Tracker with Actigraphy for Sleep Evaluation and Circadian Rest-Activity Rhythm Measurement in Healthy Young Adults. Psychiatry Investigation, 14(2), 179-185. doi:10.4306/pi.2017.14.2.179 PMID:28326116

Lee, H.-M. (2009). A study on the acceptance of wearable computers based on the extended technology acceptance model. The Research Journal of the Costume Culture, 17(6), 1155-1172. doi:10.29049/rjcc.2009.17.6.1155

Lee, M.-C. (2009a). Factors influencing the adoption of internet banking: An integration of TAM and TPB with perceived risk and perceived benefit. Electronic Commerce Research and Applications, 8(3), 130-141. doi:10.1016/j.elerap.2008.11.006

Lee, M.-C. (2009b). Predicting and explaining the adoption of online trading: An empirical study in Taiwan. Decision Support Systems, 47(2), 133-142. doi:10.1016/j.dss.2009.02.003

Lee, Y., Kozar, K. A., \& Larsen, K. R. (2003). The technology acceptance model : Past, present, and future. Communications of the Association for Information Systems, 12(1), 50. doi:10.17705/1CAIS.01250

Li, H., Wu, J., Gao, Y., \& Shi, Y. (2016). Examining individuals' adoption of healthcare wearable devices: An empirical study from privacy calculus perspective. International Journal of Medical Informatics, 88, 8-17. doi:10.1016/j.jimedinf.2015.12.010 PMID:26878757

Li, Y.-H., \& Huang, J.-W. (2009). Applying theory of perceived risk and technology acceptance model in the online shopping channel. World Academy of Science, Engineering and Technology, 53(1), 919-925.

Lian, J.-W., \& Yen, D. C. (2014). Online shopping drivers and barriers for older adults: Age and gender differences. Computers in Human Behavior, 37, 133-143. doi:10.1016/j.chb.2014.04.028 
Liang, H., Xue, Y., \& Zhang, Z. (2017). Understanding Online Health Information Use: The Case of People with Physical Disabilities. Journal of the Association for Information Systems, 18(6), 433-460. doi:10.17705/1jais.00461

Lim, N. (2003). Consumers' perceived risk: Sources versus consequences. Electronic Commerce Research and Applications, 2(3), 216-228. doi:10.1016/S1567-4223(03)00025-5

Lu, H., Hsu, C., \& Hsu, H. (2005). An empirical study of the effect of perceived risk upon intention to use online applications. Information Management \& Computer Security, 13(2), 106-120. doi:10.1108/09685220510589299

Lu, J., Yao, J. E., \& Yu, C.-S. (2005). Personal innovativeness, social influences and adoption of wireless Internet services via mobile technology. The Journal of Strategic Information Systems, 14(3), 245-268. doi:10.1016/j. jsis.2005.07.003

Lunney, A., Cunningham, N. R., \& Eastin, M. S. (2016). Wearable fitness technology: A structural investigation into acceptance and perceived fitness outcomes. Computers in Human Behavior, 65, 114-120. doi:10.1016/j. chb.2016.08.007

Lupton, D. (1999). Postmodern reflections on risk, hazards and life choices. Cambridge University Press.

Lupton, D. (2015). Quantified sex: A critical analysis of sexual and reproductive self-tracking using apps. Culture, Health \& Sexuality, 17(4), 440-453. doi:10.1080/13691058.2014.920528 PMID:24917459

Lupton, D. (2016). The diverse domains of quantified selves: Self-tracking modes and dataveillance. Economy and Society, 45(1), 101-122. doi:10.1080/03085147.2016.1143726

Mackert, M., Mabry-Flynn, A., Champlin, S., Donovan, E. E., \& Pounders, K. (2016). Health Literacy and Health Information Technology Adoption: The Potential for a New Digital Divide. Journal of Medical Internet Research, 18(10), e264. doi:10.2196/jmir.6349 PMID:27702738

Martins, C., Oliveira, T., \& Popovič, A. (2014). Understanding the Internet banking adoption: A unified theory of acceptance and use of technology and perceived risk application. International Journal of Information Management, 34(1), 1-13. doi:10.1016/j.ijinfomgt.2013.06.002

Maydeu-Olivares, A., Fairchild, A. J., \& Hall, A. G. (2017). Goodness of fit in item factor analysis: Effect of the number of response alternatives. Structural Equation Modeling, 24(4), 495-505. doi:10.1080/10705511.2 017.1289816

Mayer, R. C., Davis, J. H., \& Schoorman, F. D. (1995). An Integrative Model of Organizational Trust. Academy of Management Review, 20(3), 709-734. doi:10.5465/amr.1995.9508080335

McCoy, S., Galletta, D. F., \& King, W. R. (2007). Applying TAM across cultures: The need for caution. European Journal of Information Systems, 16(1), 81-90. doi:10.1057/palgrave.ejis.3000659

McLeod, A., Pippin, S., \& Catania, V. (2009). Using technology acceptance theory to model individual differences in tax software use. AMCIS 2009 Proceedings, 811.

McMahon, S. K., Lewis, B., Oakes, M., Guan, W., Wyman, J. F., \& Rothman, A. J. (2016). Older Adults' Experiences Using a Commercially Available Monitor to Self-Track Their Physical Activity. JMIR mHealth and uHealth, 4(2), e35-e35. doi:10.2196/mhealth.5120 PMID:27076486

Melzner, J., Heinze, J., \& Fritsch, T. (2014). Mobile Health Applications in Workplace Health Promotion: An Integrated Conceptual Adoption Framework. Procedia Technology, 16, 1374-1382. doi:10.1016/j. protcy.2014.10.155

Mercer, K., Giangregorio, L., Schneider, E., Chilana, P., Li, M., \& Grindrod, K. (2016). Acceptance of Commercially Available Wearable Activity Trackers Among Adults Aged Over 50 and With Chronic Illness: A Mixed-Methods Evaluation. JMIR mHealth and uHealth, 4(1), e7. doi:10.2196/mhealth.4225 PMID:26818775

Meyer, J., Schnauber, J., Heuten, W., Wienbergen, H., Hambrecht, R., Appelrath, H.-J., \& Boll, S. (2016). Exploring Longitudinal Use of Activity Trackers. 2016 Ieee International Conference on Healthcare Informatics (Ichi), 198-206. doi:10.1109/ICHI.2016.29 
Mieres, C., María Díaz Martín, A., \& Trespalacios Gutiérrez, J. A. (2006). Influence of perceived risk on store brand proneness. International Journal of Retail \& Distribution Management, 34(10), 761-772. doi:10.1108/09590550610691347

Miltgen, C. L., Popovič, A., \& Oliveira, T. (2013). Determinants of end-user acceptance of biometrics: Integrating the "Big 3" of technology acceptance with privacy context. Decision Support Systems, 56, 103-114. doi:10.1016/j. dss.2013.05.010

Mital, M., Chang, V., Choudhary, P., Papa, A., \& Pani, A. K. (2017). Adoption of Internet of Things in India: A test of competing models using a structured equation modeling approach. Technological Forecasting and Social Change. Advance online publication. doi:10.1016/j.techfore.2017.03.001

Moran, S., Nishida, T., \& Nakata, K. (2013). Comparing British and Japanese Perceptions of a Wearable Ubiquitous Monitoring Device. IEEE Technology and Society Magazine, 32(4), 45-49. doi:10.1109/MTS.2013.2286419

Mou, J. (2015). Trust and risk in consumer acceptance of e-services. http://wiredspace.wits.ac.za/bitstream/ handle/10539/18802/Dissertation_MouJian20150224.pdf;sequence=1

Mou, J., \& Cohen, J. (2014). Trust, risk barriers and health beliefs in consumer acceptance of online health services. Academic Press.

Mou, J., Cui, Y., \& Kurcz, K. (2020). Trust, Risk and Alternative website quality in B-buyer acceptance of cross-border E-commerce. Journal of Global Information Management, 28(1), 167-188. doi:10.4018/ JGIM.2020010109

Mou, J., Shin, D.-H., \& Cohen, J. (2016). Health beliefs and the valence framework in health information seeking behaviors. Information Technology \& People, 29(4), 876-900. doi:10.1108/ITP-06-2015-0140

Mumford, E. (1996). Risky ideas in the risk society. Journal of Information Technology, 11(4), 321.

Neill, D., Belle, J.-P. V., \& Ophoff, J. (2016). Understanding the Adoption of Wearable Technology in South African Organisations. International Conference on Information Resources Management. http://aisel.aisnet.org/ cgi/viewcontent.cgi?article $=1073 \&$ context $=$ confirm 2016

Nelson, E. C., Verhagen, T., \& Noordzij, M. L. (2016). Health empowerment through activity trackers: An empirical smart wristband study. Computers in Human Behavior, 62, 364-374. doi:10.1016/j.chb.2016.03.065

Nicolaou, A. I., Ibrahim, M., \& van Heck, E. (2013). Information quality, trust, and risk perceptions in electronic data exchanges. Decision Support Systems, 54(2), 986-996. doi:10.1016/j.dss.2012.10.024

Nicolaou, A. I., \& McKnight, D. H. (2006). Perceived Information Quality in Data Exchanges: Effects on Risk, Trust, and Intention to Use. Information Systems Research, 17(4), 332-351. doi:10.1287/isre.1060.0103

O’Brien, J. T., Gallagher, P., Stow, D., Hammerla, N., Ploetz, T., Firbank, M., Ladha, C., Ladha, K., Jackson, D., McNaney, R., Ferrier, I. N., \& Olivier, P. (2017). A study of wrist-worn activity measurement as a potential real-world biomarker for late-life depression. Psychological Medicine, 47(1), 93-102. doi:10.1017/ S0033291716002166 PMID:27667663

O'Brien, T., Troutman-Jordan, M., Hathaway, D., Armstrong, S., \& Moore, M. (2015). Acceptability of wristband activity trackers among community dwelling older adults. Geriatric Nursing, 36(2, Supplement), S21-S25. doi:10.1016/j.gerinurse.2015.02.019 PMID:25771957

Okazaki, S., Li, H., \& Hirose, M. (2009). Consumer privacy concerns and preference for degree of regulatory control. Journal of Advertising, 38(4), 63-77. doi:10.2753/JOA0091-3367380405

Okazaki, S., \& Mendez, F. (2013). Perceived Ubiquity in Mobile Services. Journal of Interactive Marketing, 27(2), 98-111. doi:10.1016/j.intmar.2012.10.001

OpinionWay. (2017). OpinionWay pour DistreeConnect 2017_Les Français et les objets connectés_Mars 2017_ Opinionway. https://www.opinion-way.com/fr/sondage-d-opinion/sondages-publies/marketing/opinionway-pourdistreeconnect-2017-les-francais-et-les-objets-econnectes-mars-2017.html

Page, T. (2015). A Forecast of the Adoption of Wearable Technology. International Journal of Technology Diffusion, 6(2), 12-29. doi:10.4018/IJTD.2015040102 
Park, D.-J., Choi, J.-H., \& Kim, D.-J. (2015). The Influence of Health Apps Efficacy, Satisfaction and Continued Use Intention on Wearable Device Adoption: A Convergence Perspective. Journal of Digital Convergence, 13(7), 137-145. doi:10.14400/JDC.2015.13.7.137

Pavlou, P. A. (2003). Consumer acceptance of electronic commerce: Integrating trust and risk with the technology acceptance model. International Journal of Electronic Commerce, 7(3), 101-134. doi:10.1080/10864415.200 3.11044275

Peng, W., Kanthawala, S., Yuan, S., \& Hussain, S. A. (2016). A qualitative study of user perceptions of mobile health apps. BMC Public Health, 16(1), 1158. doi:10.1186/s12889-016-3808-0 PMID:27842533

Peng, W., Yuan, S., \& Holtz, B. E. (2016). Exploring the Challenges and Opportunities of Health Mobile Apps for Individuals with Type 2 Diabetes Living in Rural Communities. Telemedicine Journal and e-Health, 22(9), 733-738. doi:10.1089/tmj.2015.0180 PMID:26982017

Peter, J. P., \& Tarpey, L. X. Sr. (1975). A Comparative Analysis of Three Consumer Decisions Strategies. The Journal of Consumer Research, 2(1), 29-37. doi:10.1086/208613

Pfeiffer, J., von Entress-Fuersteneck, M., Urbach, N., \& Buchwald, A. (2016). Quantify-me: Consumer Acceptance of Wearable Self-tracking Devices. ECIS 2016 Proceedings. http://aisel.aisnet.org/cgi/viewcontent.cgi?article $=1095 \&$ context $=$ ecis2016_rp

Prayoga, T., \& Abraham, J. (2016). Behavioral Intention to Use IoT Health Device: The Role of Perceived Usefulness, Facilitated Appropriation, Big Five Personality Traits, and Cultural Value Orientations. International Journal of Electrical and Computer Engineering. https://papers.ssrn.com/sol3/papers.cfm?abstract_id=2835914

Price, K., Bird, S. R., Lythgo, N., Raj, I. S., Wong, J. Y. L., \& Lynch, C. (2017). Validation of the Fitbit One, Garmin Vivofit and Jawbone UP activity tracker in estimation of energy expenditure during treadmill walking and running. Journal of Medical Engineering \& Technology, 41(3), 208-215. doi:10.1080/03091902.2016.12 53795 PMID:27919170

Pustiek, M., Beristain, A., \& Kos, A. (2015). Challenges in Wearable Devices Based Pervasive Wellbeing Monitoring. 2015 International Conference on Identification, Information, and Knowledge in the Internet of Things (IIKI), 236-243. doi:10.1109/IIKI.2015.58

Rich, E., \& Miah, A. (2017). Mobile, wearable and ingestible health technologies: Towards a critical research agenda. Health Sociology Review, 26(1), 84-97. 10.1080/14461242.2016.1211486

Ringle, C., Da Silva, D., \& Bido, D. (2015). Structural equation modeling with the SmartPLS. Academic Press.

Ringle, C. M., Sarstedt, M., \& Straub, D. (2012). A critical look at the use of PLS-SEM in MIS Quarterly. Academic Press.

Rogers, E. M. (1962). Diffusion of innovations. Simon and Schuster.

Rooksby, J., Rost, M., Morrison, A., \& Chalmers, M. C. (2014). Personal tracking as lived informatics. Proceedings of the 32nd Annual ACM Conference on Human Factors in Computing Systems, 1163-1172. https://dl.acm.org/ citation.cfm?id=2557039

Rosenberg, D., Kadokura, E. A., Bouldin, E. D., Miyawaki, C. E., Higano, C. S., \& Hartzler, A. L. (2016). Acceptability of Fitbit for physical activity tracking within clinical care among men with prostate cancer. $A M I A$ ... Annual Symposium Proceedings. AMIA Symposium, 2016, 1050-1059.

Rosenstock. (1974). The Health Belief Model and Preventive Health Behavior. Health Education Monographs, 2(4), 354-386. 10.1177/109019817400200405

Rowe, F., Ngwenyama, O., \& Richet, J.-L. (2020). Contact-tracing apps and alienation in the age of COVID-19. European Journal of Information Systems, 29(5), 1-18. doi:10.1080/0960085X.2020.1803155

Ruckenstein, M., \& Schüll, N. D. (2017). The Datafication of Health. Annual Review of Anthropology, 46(1), 261-278. doi:10.1146/annurev-anthro-102116-041244

Schaupp, L. C., Carter, L., \& McBride, M. E. (2010). E-file adoption: A study of US taxpayers' intentions. Computers in Human Behavior, 26(4), 636-644. doi:10.1016/j.chb.2009.12.017 
Scheibe, M., Reichelt, J., Bellmann, M., \& Kirch, W. (2015). Acceptance Factors of Mobile Apps for Diabetes by Patients Aged 50 or Older: A Qualitative Study. Medicine 2.0, 4(1), e1. 10.2196/med20.3912

Shafi, J., \& Waheed, A. (2019). Role of Smart Wearable in Healthcare: Wearable Internet of Medical Things (WIoMT). In The IoT and the Next Revolutions Automating the World (pp. 133-155). IGI Global. doi:10.4018/9781-5225-9246-4.ch009

Shantz, J. (2005). Beyond risk and boredom: Reflections on Claudio Ciborra and sociology. European Journal of Information Systems, 14(5), 510-512. doi:10.1057/palgrave.ejis.3000564

Sheth, J. N., Newman, B. I., \& Gross, B. L. (1991). Why we buy what we buy: A theory of consumption values. Journal of Business Research, 22(2), 159-170. doi:10.1016/0148-2963(91)90050-8

Shih, P. C., Han, K., Poole, E. S., Rosson, M. B., \& Carroll, J. M. (2015). Use and adoption challenges of wearable activity trackers. IConference 2015 Proceedings. https://www.ideals.illinois.edu/handle/2142/73649

Shin, D.-H., \& Biocca, F. (2016). Health experience model of personal informatics: The case of a quantified self. Computers in Human Behavior, 69, 62-74. doi:10.1016/j.chb.2016.12.019

Sinha, N., \& Gupta, M. (2019). Taxonomy of wearable devices: A systematic review of literature. International Journal of Technology Diffusion, 10(2), 1-17. doi:10.4018/IJTD.2019040101

Sjöklint, M., Constantiou, I. D., \& Trier, M. (2015). The Complexities of Self-tracking-An inquiry into user reactions and goal attainment. ECIS 2015 Proceedings Twenty-Third European Conference on Information Systems.

Spagnolli, A., Guardigli, E., Orso, V., Varotto, A., \& Gamberini, L. (2014). Measuring User Acceptance of Wearable Symbiotic Devices: Validation Study Across Application Scenarios. In G. Jacucci, L. Gamberini, J. Freeman, \& A. Spagnolli (Eds.), Symbiotic Interaction (Vol. 8820, pp. 87-98). Academic Press.

Stone, R. N., \& Grønhaug, K. (1993). Perceived risk: Further considerations for the marketing discipline. European Journal of Marketing, 27(3), 39-50. doi:10.1108/03090569310026637

Stragier, J., Evens, T., \& Mechant, P. (2015). Broadcast Yourself: An Exploratory Study of Sharing Physical Activity on Social Networking Sites. Media International Australia, 155(1), 120-129. doi:10.1177/1329878X1515500114

Su, Y., \& Gururajan, R. (2010). The Determinants for Adoption of Wearable Computer Systems in Traditional Chinese Hospital. 2010 Asia-Pacific Conference on Wearable Computing Systems, 375-378. doi:10.1109/ APWCS.2010.102

Sun, N., \& Rau, P.-L. P. (2015). The acceptance of personal health devices among patients with chronic conditions. International Journal of Medical Informatics, 84(4), 288-297. doi:10.1016/j.jimedinf.2015.01.002 PMID:25655783

Thielke, S., Harniss, M., Thompson, H., Patel, S., Demiris, G., \& Johnson, K. (2012). Maslow's Hierarchy of Human Needs and the Adoption of Health-Related Technologies for Older Adults. Ageing International, 37(4), 470-488. doi:10.1007/s12126-011-9121-4

Ticsante. (2017). Objets connectés: 8 Français sur 10 prêts à être équipés pour suivre leur maladie chronique (enquête Unicancer). https://www.ticsante.com/story/3750/objets-connectes-8-francais-sur-10-prets-a-etreequipes-pour-suivre-leur-maladie-chronique-(enquete-unicancer).html

Turel, O., Matt, C., Trenz, M., \& Cheung, C. M. K. (2020). An intertwined perspective on technology and digitised individuals : Linkages, needs and outcomes. Information Systems Journal, 30(6), 929-939. Advance online publication. doi:10.1111/isj.12304

Tuzovic, S. (2015). The Rise of Self-Tracking. 2015 Australian and New Zealand Marketing Academy (ANZMAC) Conference.

Van Langenhove, L., Hertleer, C., \& Schwarz, A. (2012). Smart textiles: An overview. In Intelligent textiles and clothing for ballistic and NBC protection (pp. 119-136). Springer. doi:10.1007/978-94-007-0576-0_6

Venkatesh, V., Morris, M. G., Davis, G. B., \& Davis, F. D. (2003). User acceptance of information technology: Toward a unified view. Management Information Systems Quarterly, 27(3), 425-478. doi:10.2307/30036540 
Venkatesh, V., Thong, J. Y., \& Xu, X. (2012). Consumer acceptance and use of information technology: Extending the unified theory of acceptance and use of technology. Management Information Systems Quarterly, 36(1), 157-178. doi:10.2307/41410412

Venkatesh, V., Thong, J. Y. L., \& Xu, X. (2016). Unified Theory of Acceptance and Use of Technology: A Synthesis and the Road Ahead. Journal of the Association for Information Systems, 17(5), 328-376. doi: $10.17705 / 1$ jais.00428

Verhagen, T., Meents, S., \& Tan, Y.-H. (2006). Perceived risk and trust associated with purchasing at electronic marketplaces. European Journal of Information Systems, 15(6), 542-555. doi:10.1057/palgrave.ejis.3000644

Vodanovich, S., Sundaram, D., \& Myers, M. (2010). Digital Natives and Ubiquitous Information Systems. Information Systems Research, 21(4), 711-723. doi:10.1287/isre.1100.0324

Voth, E. C., Oelke, N. D., \& Jung, M. E. (2016). A Theory-Based Exercise App to Enhance Exercise Adherence: A Pilot Study. JMIR mHealth and uHealth, 4(2), e62. doi:10.2196/mhealth.4997 PMID:27307134

Waltzer, S. (2020). Global Smartwatch Shipments Grow 20 Percent to 14 Million in Q1 2020. Strategy Analytics.

Wang, T., Jung, C.-H., Kang, M.-H., \& Chung, Y.-S. (2014). Exploring determinants of adoption intentions towards Enterprise 2.0 applications: An empirical study. Behaviour \& Information Technology, 33(10), 10481064. doi:10.1080/0144929X.2013.781221

Weber, S. (2015). How Can Scientific and Technological Breakthroughs Be Accelerated to Improve the Human Condition? In Grand Societal Challenges in Information Systems Research and Education (pp. 77-85). Springer. doi:10.1007/978-3-319-15027-7_9

Weinstein, N. D. (1993). Testing four competing theories of health-protective behavior. Health Psychology, 12(4), 324-333. doi:10.1037/0278-6133.12.4.324 PMID:8404807

Wen, D., Zhang, X., \& Lei, J. (2017). Consumers' perceived attitudes to wearable devices in health monitoring in China: A survey study. Computer Methods and Programs in Biomedicine, 140, 131-137. doi:10.1016/j. cmpb.2016.12.009 PMID:28254069

WHO Global Observatory for eHealth \& World Health Organization. (2011). MHealth: New horizons for health through mobile technologies. World Health Organization. https:/www.who.int/goe/publications/ goe_mhealth_web.pdf

Wu, I.-L., Li, J.-Y., \& Fu, C.-Y. (2011). The adoption of mobile healthcare by hospital's professionals: An integrative perspective. Decision Support Systems, 51(3), 587-596. doi:10.1016/j.dss.2011.03.003

Wu, J., \& Gaytán, E. A. A. (2013). The role of online seller reviews and product price on buyers' willingnessto-pay: A risk perspective. European Journal of Information Systems, 22(4), 416-433. doi:10.1057/ejis.2012.33

Wu, J., Wu, Y., Sun, J., \& Yang, Z. (2013). User reviews and uncertainty assessment: A two stage model of consumers' willingness-to-pay in online markets. Decision Support Systems, 55(1), 175-185. doi:10.1016/j. dss.2013.01.017

Wu, K., Zhao, Y., Zhu, Q., Tan, X., \& Zheng, H. (2011). A meta-analysis of the impact of trust on technology acceptance model: Investigation of moderating influence of subject and context type. International Journal of Information Management, 31(6), 572-581. doi:10.1016/j.ijinfomgt.2011.03.004

Wu, L.-H., Wu, L.-C., \& Chang, S.-C. (2016). Exploring consumers' intention to accept smartwatch. Computers in Human Behavior, 64, 383-392. doi:10.1016/j.chb.2016.07.005

Yang, H., Yu, J., Zo, H., \& Choi, M. (2016). User acceptance of wearable devices: An extended perspective of perceived value. Telematics and Informatics, 33(2), 256-269. doi:10.1016/j.tele.2015.08.007

Yang, J., Sarathy, R., \& Lee, J. (2016). The effect of product review balance and volume on online Shoppers' risk perception and purchase intention. Decision Support Systems, 89, 66-76. doi:10.1016/j.dss.2016.06.009

Yoganathan, D., \& Kajanan, S. (2014). What Drives Fitness Apps Usage? An Empirical Evaluation. International Working Conference on Transfer and Diffusion of IT, 179-196. https://link.springer.com/ chapter/10.1007/978-3-662-43459-8_12 
Yuan, S., Ma, W., Kanthawala, S., \& Peng, W. (2015). Keep using my health apps: Discover users' perception of health and fitness apps with the UTAUT2 model. Telemedicine Journal and e-Health, 21(9), 735-741. doi:10.1089/tmj.2014.0148 PMID:25919238

Zhang, L., Tan, W., Xu, Y., \& Tan, G. (2012). Dimensions of consumers' perceived risk and their influences on online consumers' purchasing behavior. Communications in Information Science and Management Engineering, 2(7). 


\section{APPENDIX I.}

\section{The Three dimensions of ST in the models}

\section{Table 15}

\begin{tabular}{|c|c|c|c|}
\hline Authors & Technological & Medical & Social \\
\hline (Baumgart \& Wiewiorra, 2016) & $\mathrm{X}$ & $\mathrm{x}$ & \\
\hline (Cho et al., 2015) & $\mathrm{X}$ & $\mathrm{X}$ & $\mathrm{X}$ \\
\hline (Choi \& Kim, 2016) & $\mathrm{X}$ & & \\
\hline (Choi et al., 2017) & $\mathrm{X}$ & $\mathrm{X}$ & $\mathrm{X}$ \\
\hline (Chuah et al., 2016) & $\mathrm{X}$ & & $\mathrm{X}$ \\
\hline (Deng et al., 2014) & $\mathrm{X}$ & $\mathrm{X}$ & $\mathrm{X}$ \\
\hline (Ella Carter, 2013) & $\mathrm{X}$ & & \\
\hline (Fensli et al., 2008) & $\mathrm{X}$ & $\mathrm{X}$ & \\
\hline (Gao et al., 2015) & $\mathrm{X}$ & $\mathrm{X}$ & $\mathrm{x}$ \\
\hline (Gao et al., 2016) & $\mathrm{X}$ & & $\mathrm{X}$ \\
\hline (Gilbert \& Namagembe, 2013) & $\mathrm{X}$ & & $\mathrm{X}$ \\
\hline (Hirose \& Tabe, 2016) & $\mathrm{X}$ & $\mathrm{x}$ & $\mathrm{X}$ \\
\hline (Hoque \& Sorwar, 2017) & $\mathrm{X}$ & & $\mathrm{X}$ \\
\hline (Hsiao \& Chen, 2017) & $\mathrm{X}$ & & $\mathrm{X}$ \\
\hline (Huang \& Lai, 2016) & $\mathrm{X}$ & & \\
\hline (Kim \& Shin, 2015) & $\mathrm{X}$ & & $\mathrm{X}$ \\
\hline (Lee et al., 2017) & $\mathrm{X}$ & $\mathrm{X}$ & \\
\hline (Li et al., 2016) & $\mathrm{X}$ & & $\mathrm{X}$ \\
\hline (Lunney et al., 2016) & $\mathrm{X}$ & & $\mathrm{X}$ \\
\hline (Maltseva \& Lutz, 2018) & & & $\mathrm{X}$ \\
\hline (Marakhimov \& Joo, 2017) & & $\mathrm{X}$ & $\mathrm{X}$ \\
\hline (Mital et al., 2017) & $\mathrm{X}$ & & $\mathrm{X}$ \\
\hline (Ogbanufe \& Gerhart, 2017) & $\mathrm{X}$ & & \\
\hline (Okumus et al., 2018) & $\mathrm{X}$ & & $\mathrm{X}$ \\
\hline (Park et al., 2015) & $\mathrm{X}$ & & \\
\hline (Pfeiffer et al., 2016) & $\mathrm{X}$ & $\mathrm{x}$ & $\mathrm{X}$ \\
\hline (Prayoga \& Abraham, 2016) & $\mathrm{X}$ & & \\
\hline (Song et al., 2017) & $\mathrm{X}$ & & $\mathrm{X}$ \\
\hline (Spagnolli et al., 2014) & $\mathrm{X}$ & & \\
\hline (Su \& Gururajan, 2010) & $\mathrm{X}$ & & $\mathrm{X}$ \\
\hline (Wu et al., 2011) & $\mathrm{X}$ & & $\mathrm{X}$ \\
\hline (Wu et al., 2016) & $\mathrm{X}$ & & $\mathrm{X}$ \\
\hline (Yang et al., 2016) & $\mathrm{X}$ & & $\mathrm{X}$ \\
\hline (Yoganathan \& Kajanan, 2014) & $\mathrm{X}$ & & $\mathrm{X}$ \\
\hline (Yuan et al., 2015) & $\mathrm{X}$ & & $\mathrm{X}$ \\
\hline (Zhang et al., 2017) & $\mathrm{X}$ & $\mathrm{X}$ & $\mathrm{X}$ \\
\hline
\end{tabular}




\section{APPENDIX II.}

\section{The Main Variables From The Models}

Table 16.

\begin{tabular}{|c|c|c|c|}
\hline $\begin{array}{l}\text { Theoretical } \\
\text { constructs }\end{array}$ & Definition & $\begin{array}{l}\text { Article } \\
\text { counts }\end{array}$ & $\begin{array}{l}\text { Associated } \\
\text { adoption } \\
\text { theories }\end{array}$ \\
\hline $\begin{array}{l}\text { Perceived } \\
\text { usefulness }\end{array}$ & $\begin{array}{l}\text { Perceived usefulness can be defined as the extent to which a person believes that } \\
\text { using a particular system would be helpful and enhance performance (Davis,1986) }\end{array}$ & 32 & TAM \\
\hline $\begin{array}{l}\text { Perceived ease } \\
\text { of use }\end{array}$ & $\begin{array}{l}\text { Perceived ease of use refers to the degree to which the prospective user expects the } \\
\text { target system to be free of effort in use (Wu et al. 2011) }\end{array}$ & 23 & TAM \\
\hline Subjective norms & $\begin{array}{l}\text { Subjective norms illustrate how others impact one's motivation to exercise or live } \\
\text { a healthy lifestyle, and, as a result, adopt a WFT device (Lunney et al. 2016) }\end{array}$ & 14 & TRA \\
\hline $\begin{array}{l}\text { Behavioral } \\
\text { intention }\end{array}$ & $\begin{array}{l}\text { Behavioral intention is a measure of the strength of one's willingness to try and } \\
\text { exert while performing certain behavior. (Wu et al. 2011), The user's desire to } \\
\text { accept a particular system(Davis 1989) }\end{array}$ & 18 & TRA \\
\hline $\begin{array}{l}\text { Attitude towards } \\
\text { actor behavior }\end{array}$ & The possibility of a user to accept a particular system (Davis, 1989) & 11 & TRA \\
\hline $\begin{array}{l}\text { Performance } \\
\text { Expectancy }\end{array}$ & $\begin{array}{l}\text { Performance Expectancy of fitness app is defined as the degree to which an } \\
\text { individual believes that using the fitness app will help him/her to attain gains in } \\
\text { physical activity performance or achieve physical activity goals. (Yoganathan et } \\
\text { al. 2011) }\end{array}$ & 11 & UTAUT \\
\hline $\begin{array}{l}\text { Facilitating } \\
\text { Conditions }\end{array}$ & $\begin{array}{l}\text { Facilitating conditions are explained as factors in the environment that either } \\
\text { facilitate or impede acceptance of technology (Venkatesh, 2000). Facilitating } \\
\text { conditions are similar to the concept of perceived behavioral control in TPB. } \\
\text { According to TPB, perceived behavioral control is derived from two sources: the } \\
\text { external and the internal control (Ajzen, 1991) }\end{array}$ & 10 & UTAUT \\
\hline Effort Expectancy & $\begin{array}{l}\text { Effort expectancy is widely known as the degree of ease related to consumer'suse } \\
\text { of technology (Venkatesh et al., 2012). In healthcare wearable device context, } \\
\text { effort expectancy is introduced to measure consumer's perceived ease of using } \\
\text { wearable devices in healthcare (Gao 2015) }\end{array}$ & 9 & UTAUT \\
\hline $\begin{array}{l}\text { Perceived } \\
\text { behavioral control }\end{array}$ & $\begin{array}{l}\text { Perceived behavioral control considers control beliefs and ability to influence } \\
\text { these belief. Perceived behavioral control examines control over behavior and } \\
\text { ability to influence behavior. In the case of technology, technology may be either } \\
\text { a positive or negative control variable in that it may encourage or prevent exercise. } \\
\text { (Herrmann et al. 2017) }\end{array}$ & 8 & TPB \\
\hline Enjoyment & & 7 & \\
\hline $\begin{array}{l}\text { Perception of } \\
\text { Privacy }\end{array}$ & & 7 & \\
\hline Perception of Trust & $\begin{array}{l}\text { The extent to which a person believes that using a particular system would be safe } \\
\text { and high quality (Gefen et al. 2003) }\end{array}$ & 7 & \\
\hline $\begin{array}{l}\text { Attitude Toward } \\
\text { Technology }\end{array}$ & a positive or negative view of the application of a technology (Moran 2013) & 7 & TAM \\
\hline $\begin{array}{l}\text { Hedonic } \\
\text { Motivation }\end{array}$ & $\begin{array}{l}\text { refers to the pleasure or enjoyment derived from adopting and using a technology } \\
\text { (Venkatesh et al., 2012) }\end{array}$ & 7 & UTAUT2 \\
\hline Price Value & & 7 & UTAUT2 \\
\hline
\end{tabular}


Table 16. Continued

\begin{tabular}{|c|c|c|c|}
\hline $\begin{array}{l}\text { Theoretical } \\
\text { constructs }\end{array}$ & Definition & $\begin{array}{l}\text { Article } \\
\text { counts }\end{array}$ & $\begin{array}{c}\text { Associated } \\
\text { adoption } \\
\text { theories }\end{array}$ \\
\hline $\begin{array}{l}\text { Personal } \\
\text { Innovativeness }\end{array}$ & $\begin{array}{l}\text { personal innovativeness refers to the willingness of a potential user to try out new } \\
\text { information technology since wearable self-tracking devices are a very new and } \\
\text { relatively unknown technology (Pfeiffer et al. 2016) }\end{array}$ & 6 & \\
\hline Self-efficacy & $\begin{array}{l}\text { Self-efficacy is a set of beliefs one has about his/her ability to organize and } \\
\text { complete a task in order to accomplish a certain task that is crucial for eliciting } \\
\text { health behavior change [22] (Bandura 1977) }\end{array}$ & 6 & SCT \\
\hline Compatibility & $\begin{array}{l}\text { the degree to which wearable devices comply with other products' (e.g., } \\
\text { smartphones, PCs) technical functionalities, users' business needs and lifestyles } \\
\text { (Yu et al. 2016) }\end{array}$ & 5 & DOI \\
\hline $\begin{array}{l}\text { Aesthetically } \\
\text { Design }\end{array}$ & & 5 & \\
\hline Comfort & $\begin{array}{l}\text { The extent to which a potential customer's value, self-demand, precious } \\
\text { experiment are matching with a particular system (Rogers, 1995) }\end{array}$ & 5 & DOI \\
\hline Anxiety & $\begin{array}{l}\text { Technology anxiety is a negative emotional response, and pertains to the fear or } \\
\text { discomfort people experience when they think of using or actually use technology } \\
\text { [71]. It also refers to the apprehension of an individual when he or she is faced } \\
\text { with the possibility of using technology. Technology anxiety is derived from social } \\
\text { cognitive theory [72]. (Deng 2013) }\end{array}$ & 4 & SCT \\
\hline Perceived Value & $\begin{array}{l}\text { this study refers to the perceived value of wearable devices as a potential } \\
\text { customer's overall perception of wearable devices based on their beneðts and } \\
\text { sacriðces (Yang et al. 2016) }\end{array}$ & 3 & \\
\hline Habit & $\begin{array}{l}\text { "the extent to which people tend to perform behaviors (use IS) automatically } \\
\text { because of learning" (Limayem et al. 2007, p. 709). }\end{array}$ & 3 & UTAUT2 \\
\hline
\end{tabular}




\section{APPENDIX III.}

\section{All The Variables}

Table 17.

\begin{tabular}{|c|c|c|c|c|}
\hline & & No & $\underset{m e d}{N a}$ & \\
\hline \multicolumn{5}{|c|}{ Tool caracteristic } \\
\hline & Brand & 2 & $\mathbf{3}$ & Brand Name(1), Brand Familianity(2) \\
\hline \multicolumn{2}{|r|}{ Comfort } & 3 & 10 & Comfortable(8), Acceptability (1), Wearabiaity (1) \\
\hline & Esthetic & 4 & 12 & $\begin{array}{l}\text { Aesthetically Design(9), Apearance cvaluation(1), Appearance Oricutation(1), Visual } \\
\text { Attractiveness(1) }\end{array}$ \\
\hline \multicolumn{5}{|c|}{ Function } \\
\hline & Informention & $\mathbf{1}$ & $\mathbf{1}$ & Percelved Informativeness(1), \\
\hline & Mobile & 3 & 7 & Mobility(3), Ubiquity(3), Distubance concems(1) \\
\hline & Opewess & 4 & 12 & Compatibility (7), Commericability (3), Inter-operability (1), Pensonaleration concem(1) \\
\hline & Playfal & 2 & 10 & Frijoyment(8), Perocived Playfulness(2) \\
\hline & Reliability & 9 & 21 &  \\
\hline & Perfornamce & 4 & 17 & $\begin{array}{l}\text { App Efficacy(1), Perocived Service Availability(1), Relative Advantage(3), Performance } \\
\text { Bxpectancy(12) }\end{array}$ \\
\hline & Sipport & $\mathbf{s}$ & & $\begin{array}{l}\text { Support of Fituess( (1), Sepport of Healh(1), Support of Wel-Being(1), Management } \\
\text { suppont(1), Level of exercioe encouragement(1) }\end{array}$ \\
\hline & Imeovation & 6 & 12 & 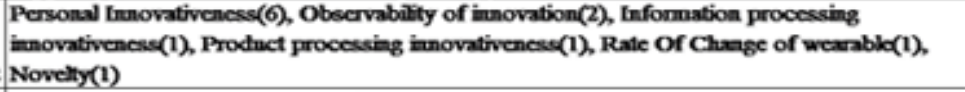 \\
\hline & Value & $\mathbf{2}$ & 15 & Price Vahed(10), Peroeived Vahed(5) \\
\hline & Secarity/Privacy & 9 & 21 & $\begin{array}{l}\text { Perception of Privacy(9), Data Security(2), Perceivod Privacy Invasion(2), Leginhation } \\
\text { Protection(1), Security(1), Sharing Personal Information(1), Transparency(1), Safety(3), } \\
\text { Information Senvitivity(1) }\end{array}$ \\
\hline & & & & \\
\hline \multicolumn{5}{|c|}{ Person } \\
\hline & Beliefs about tech & 4 & 25 & 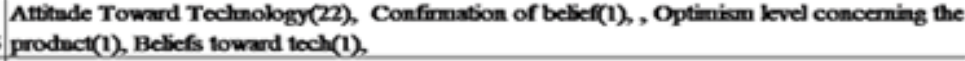 \\
\hline & Behavior & 3 & 29 & Behavional intention(18), Bxercice Behavior(2), Perceived behavional control(9) \\
\hline & Selr Capabinity & 11 & 20 & 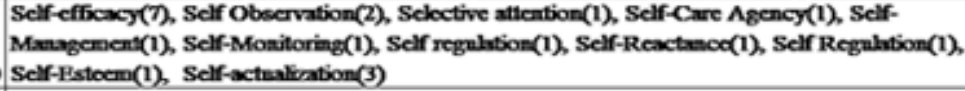 \\
\hline & Ease to use & 6 & 59 & $\begin{array}{l}\text { Base of nse(30), Faciltating Conditions(12), Effort Expectancy(11), Complexily (2), Relative } \\
\text { advantage(2), Barricr to nse(2) }\end{array}$ \\
\hline & Techmophing & $\mathbf{1}$ & 2 & Omenhip of ICT gadget(2) \\
\hline & Habit/Rontine & $\mathbf{3}$ & $\mathbf{8}$ & Habitt(4), Perceived routine constraints(3), cognitive inertin(1) \\
\hline & Healm & 7 & 9 & $\begin{array}{l}\text { Perceived Severity(2), Health Cognitive(2), Health Arobiety(1), Health Control bebef(1), Health } \\
\text { Stress(1), Hygenic Aspects(1), Shin Reactions(1) }\end{array}$ \\
\hline & Fitmess & 4 & & $\begin{array}{l}\text { Percedvod Physical Condition(3), Fituess Bvaluation(1), Fitness Orientation(1), Physical } \\
\text { Activity(1) }\end{array}$ \\
\hline & Knowledge & 6 & 10 & $\begin{array}{l}\text { Technology Expertise(3), IT Knowlodge(2), Medical Litteracy(2), Neod for Cognition(1), } \\
\text { Prior Knowlodga(1), Tech sapport and training(1) }\end{array}$ \\
\hline & Motivation & $\mathbf{s}$ & 15 & $\begin{array}{l}\text { Hedonic Motivation(9), Self Expression Motivated(2), Intrinsic Motivation for Physical } \\
\text { Activity(1), Level of Interest(1), Cue To Action(2) }\end{array}$ \\
\hline & Need & $\mathbf{s}$ & $\mathbf{s}$ & $\begin{array}{l}\text { Physiological nood(3), Love and Belonging(2),Neod For Uniqueness(1), Nood for } \\
\text { Materinliun(1), Gratification(1) }\end{array}$ \\
\hline & Psycho & 10 & 11 &  \\
\hline & Rink & 4 & 7 & Perceived Rivks(3), Performamoe rivl:(1), Privacy Rivh(2), Fimmcial Rivk(1) \\
\hline & Trait & 11 & 19 & 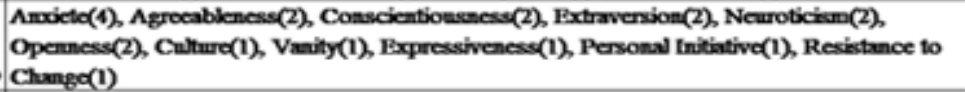 \\
\hline & Usefulness & 6 & so & $\begin{array}{l}\text { Perceivod usefulness(41), System capability shortcomings(2), Fanctional Congruence(2), } \\
\text { Usability (1), Perceived Beneffit(3), App Satisfaction(1) }\end{array}$ \\
\hline Serial & & 13 & & 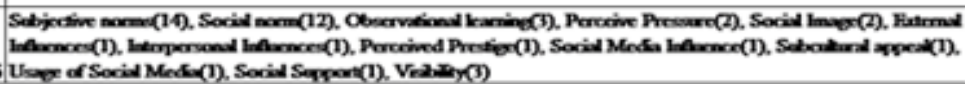 \\
\hline
\end{tabular}




\section{APPENDIX IV.}

\section{Different Aspects of Risk}

Table 18.

\begin{tabular}{|c|c|}
\hline Perceived Risk Facet & Description-Definition \\
\hline Perceived Financial Risk & $\begin{array}{l}\text { "The potential monetary outlay associated with the initial purchase price as well as the } \\
\text { subsequent maintenance cost of the product" (Grewal et al., 1994). }\end{array}$ \\
\hline Perceived performance risk & $\begin{array}{l}\text { "The possibility of the product malfunctioning and not performing as it was designed } \\
\text { and advertised and therefore failing to deliver the desired beneðts." (Grewal et al., } \\
\text { 1994) } \\
\text { "This dimension of perceived risk is similar to the usefulness or functionality of } \\
\text { products".(Lim, 2003) }\end{array}$ \\
\hline Perceived social risk & $\begin{array}{l}\text { "Potential loss of status in one's social group as a result of adopting a product or } \\
\text { service, looking foolish or untrendy" (Featherman \& Pavlou, 2003) }\end{array}$ \\
\hline Perceived physical risk & $\begin{array}{l}\text { "is the possibility that products are harmful to individuals' health or products do not } \\
\text { look as good as the individuals expect" (Lim, 2003) }\end{array}$ \\
\hline Perceived psychological risk & $\begin{array}{l}\text { "The risk that the selection or performance of the producer will have a negative effect } \\
\text { on the consumer's peace of mind or self-perception (Mitchell, 1992). Potential loss of } \\
\text { self-esteem (ego loss) from the frustration of not achieving a buying goal."(Featherman } \\
\text { \& Pavlou, 2003) } \\
\text { "In addition to shopping time, this dimension includes waiting time for receipt of } \\
\text { products as well as time spent on returning unsatisfactory products" (Lim, 2003) }\end{array}$ \\
\hline Perceived time-loss risk & $\begin{array}{l}\text { "Consumers may lose time when making a bad purchasing decision by wasting time } \\
\text { researching and making the purchase, learning how to use a product or service only to } \\
\text { have to replace it if it does not perform to expectations."(Featherman \& Pavlou, 2003) } \\
\text { "In addition to shopping time, this dimension includes waiting time for receipt of } \\
\text { products as well as time spent on returning unsatisfactory products" (Lim, 2003) }\end{array}$ \\
\hline Perceived personal risk & $\begin{array}{l}\text { "is the possibility that individuals may be harmed because of their purchase behavior. } \\
\text { For example, they are likely to suffer if their credit cards information is stolen." (Lim, } \\
\text { 2003) }\end{array}$ \\
\hline Perceived privacy risk & $\begin{array}{l}\text { "Potential loss of control over personal information, such as when information about } \\
\text { you is used without your knowledge or permission. The extreme case is where a } \\
\text { consumer is "spoofed" meaning a criminal uses their identity to perform fraudulent } \\
\text { transactions." (Featherman \& Pavlou, 2003) } \\
\text { "This dimension of risk includes undisclosed capture of information like consumers' } \\
\text { shopping habits." (Lim, 2003) }\end{array}$ \\
\hline Quality risk & $\begin{array}{l}\text { "The possibility of the product malfunctioning and not performing as it was designed } \\
\text { and advertised and therefore failing to deliver the desired benefits" (Zhang et al., 2012) }\end{array}$ \\
\hline Health risk & $\begin{array}{l}\text { "Potential loss of health because of prolonged use of computer will cause fatigue or } \\
\text { visually impaired, pressure on one's heart, or buying counterfeit products which is } \\
\text { harmful to one's health" (Zhang et al., 2012) }\end{array}$ \\
\hline Economic risk & $\begin{array}{l}\text { "The potential monetary outlay associated with the initial purchase price as well as } \\
\text { the subsequent maintenance cost of the product, and the potential financial loss due to } \\
\text { fraud" (Zhang et al., 2012) }\end{array}$ \\
\hline Overall risk & $\begin{array}{l}\text { "A general measure of perceived risk when all criteria are evaluated together." } \\
\text { (Featherman \& Pavlou, 2003) }\end{array}$ \\
\hline
\end{tabular}




\section{APPENDIX V.}

\section{The Concept of Risk in IS Research}

Table 19.

\begin{tabular}{|c|c|c|c|}
\hline Authors & Technology & Theory & Risk Type \\
\hline McLeod, Pippin, \& Catania (2009) & Tax software & UTAUT & Perceived Risk \\
\hline (Cocosila et al., 2009) & New technology & Motivation theory & $\begin{array}{l}\text { Finance, Social, Privacy, } \\
\text { Psychology }\end{array}$ \\
\hline Lian \& Yen (2014) & Online shopping & $\begin{array}{l}\text { Innovation resistance theory and } \\
\text { UTAUT }\end{array}$ & Risk barrier \\
\hline Schaupp, Carter, \& McBride (2010) & E-file Taxe & UTAUT & Perceived Risk \\
\hline (Horst et al., 2007) & E-government services & ТPB & Risk Perception \\
\hline Miltgen, Popovic, \& Oliveira (2013) & Biometrics & TAM, DOI, UTAUT & Perceived Risk \\
\hline (Ayanso et al., 2015) & $\begin{array}{l}\text { Electronic Medical } \\
\text { Record }\end{array}$ & Expectation-Confirmation Theory & $\begin{array}{l}\text { Performance, Finance, } \\
\text { Time, Psychological, Social, } \\
\text { Privacy, Overall }\end{array}$ \\
\hline (Kim et al., 2008) & E-commerce & Valence Framework & Perceived Risk \\
\hline (Lee, 2009) & Online trading & TAM, TPB, Rational Choice & Perceived Risk \\
\hline (Nicolaou \& McKnight, 2006) & Quality Data Exchange & Risk Theory, IS Success Model & Perceived Risk \\
\hline (Yang et al., 2016) & Website & TRA & $\begin{array}{l}\text { Finance, performance, } \\
\text { psychological, social risk }\end{array}$ \\
\hline (Dinev et al., 2006) & e-commerce & Privacy calculus & Perceived Risk \\
\hline (Verhagen et al., 2006) & e-commerce & TRA & Intermediary and seller risk \\
\hline (Lu et al., 2005) & Online applications & TAM & $\begin{array}{l}\text { Physical, Functional, } \\
\text { Social, Time-loss, } \\
\text { Financial, Opportunity cost, } \\
\text { Information }\end{array}$ \\
\hline (Anderson \& Agarwal, 2011) & $\begin{array}{l}\text { Disclose Personal } \\
\text { Health information }\end{array}$ & Privacy calculus and Risk as feelings & Risk as feeling \\
\hline (Featherman \& Pavlou, 2003) & e-service & Perceived Risk Theory, TAM & $\begin{array}{l}\text { Performance, Financial, } \\
\text { Time, Psychological, Social, } \\
\text { Privacy, Overall }\end{array}$ \\
\hline Martins, Oliveira, \& Popovic (2014) & Internet Banking & UTAUT & $\begin{array}{l}\text { Performance, Finance, } \\
\text { Time, Psychological, Social, } \\
\text { Privacy, Overall }\end{array}$ \\
\hline (Aytes \& Connolly, 2004) & Computer security & Rational Choice theory & $\begin{array}{l}\text { Probability of negative } \\
\text { consequences }\end{array}$ \\
\hline (Huigang Liang et al., 2017) & $\begin{array}{l}\text { Online Health } \\
\text { Information }\end{array}$ & $\begin{array}{l}\text { Rational Choice Theory, IS Success } \\
\text { Model }\end{array}$ & Perceived Risk \\
\hline (Hong \& L. Thong, 2013) & $\begin{array}{l}\text { Internet Privacy } \\
\text { Concern }\end{array}$ & Not Applicable (Literature review) & Risk Belief \\
\hline (Bulgurcu et al., 2010) & Computer security & Rational Choice theory, TPB & Benefit-Cost of Compliance \\
\hline (Li \& Huang, 2009) & Online shopping & TAM & $\begin{array}{l}\text { Performance, Finance, } \\
\text { Time, Psychological, Social, } \\
\text { Privacy, Overall }\end{array}$ \\
\hline
\end{tabular}




\section{APPENDIX VI.}

\section{The Survey}

Table 20.

\begin{tabular}{|c|c|}
\hline Cencept & The servey \\
\hline \multicolumn{2}{|r|}{ Fase of Use } \\
\hline $\begin{array}{l}\text { Modified 4 dement seale based en } \\
\text { (Pfoiffer et al, 2016) on Ven'ritesh et } \\
\text { al (2003). La it all (2005) and Gefen } \\
\text { ct al (2003). }\end{array}$ &  \\
\hline \multicolumn{2}{|r|}{ Ubiquity } \\
\hline 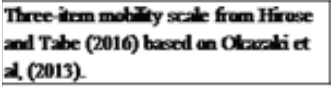 &  \\
\hline \multicolumn{2}{|r|}{ Seppert to Heallh } \\
\hline $\begin{array}{l}\text { Modified 5-dement seale based an } \\
\text { (Pficifiex et al, 2016) }\end{array}$ & 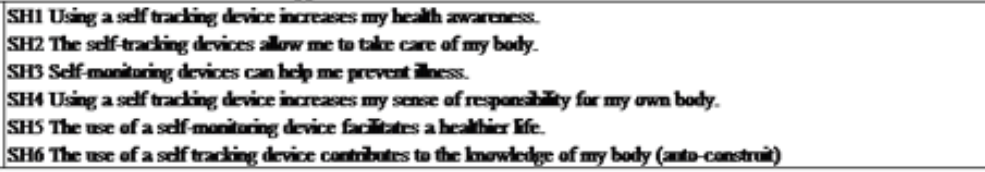 \\
\hline \multicolumn{2}{|r|}{ Secial Nerins } \\
\hline $\begin{array}{l}\text { Modified 5-element scale based an } \\
\text { Pficiffer ot al (2016) based an } \\
\text { Venletresh et al (2012) }\end{array}$ &  \\
\hline \multicolumn{2}{|r|}{ Trust-Bemeveleace } \\
\hline $\begin{array}{l}\text { Modified 4 dement scale accorifing to } \\
\text { Mou \& Cahen, (2014) }\end{array}$ &  \\
\hline \multicolumn{2}{|c|}{ Trest-Internity } \\
\hline $\begin{array}{l}\text { Modified 4-dement scale accoriling to } \\
\text { Mou \& Cohen, (2014) }\end{array}$ & 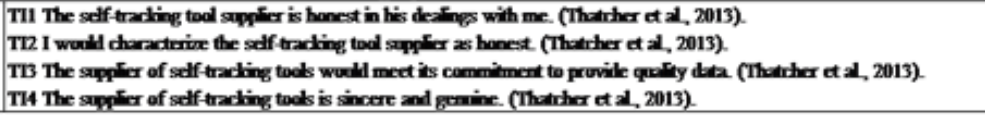 \\
\hline \multicolumn{2}{|r|}{ Trest-Ab-ity } \\
\hline $\begin{array}{l}\text { Modified 4-dement scale accoriling to } \\
\text { Mou \& Cuhen, (2014) }\end{array}$ &  \\
\hline \multicolumn{2}{|r|}{ Flysical Risk } \\
\hline $\begin{array}{l}\text { Modified 3- dement seale based an } \\
\text { (Gurtner, 2014) fram Mieres, Martin, } \\
\text { and Gutilrex (2006) }\end{array}$ & $\begin{array}{l}\text { PHR1 Fm afrid the self-tracking devices aren't safe far me. } \\
\text { PHR2 Tm afrid that the sedf-traching devices maxy be damaging to my hedith. } \\
\text { PHR3 I think the self tracking devices can canse me physical damage. }\end{array}$ \\
\hline \multicolumn{2}{|r|}{ Perforinace Risk } \\
\hline $\begin{array}{l}\text { Modified 3 clement scale based on } \\
\text { (Yang et al, 2016) after Gewal et al. } \\
\text { (1994) and Stane and Grinheng (1993). }\end{array}$ & $\begin{array}{l}\text { PER1 I am concemed that the self tracking devices wil not provile the kevel of benefits I expect. } \\
\text { PER2. It is not certin that the self tracking devices will function satiffacturily. } \\
\text { PER3 it is not certin that the self-tracking devices wil perform the finctions deseribed in the alvertisement. }\end{array}$ \\
\hline \multicolumn{2}{|r|}{ Privite Risk } \\
\hline $\begin{array}{l}\text { Modified 3-dement seale based an (Ii } \\
\text { ot al 2016) }\end{array}$ &  \\
\hline \multicolumn{2}{|r|}{ Inlentine to ese } \\
\hline $\begin{array}{l}\text { Modified 4 clement scale ancoring to } \\
\text { Pficiffer ot al (2016) bxed an } \\
\text { Venl-atesh (2012) }\end{array}$ &  \\
\hline
\end{tabular}




\section{APPENDIX VII.}

First Step in The Construction of a Second Order Model

Figure 5.

First Order

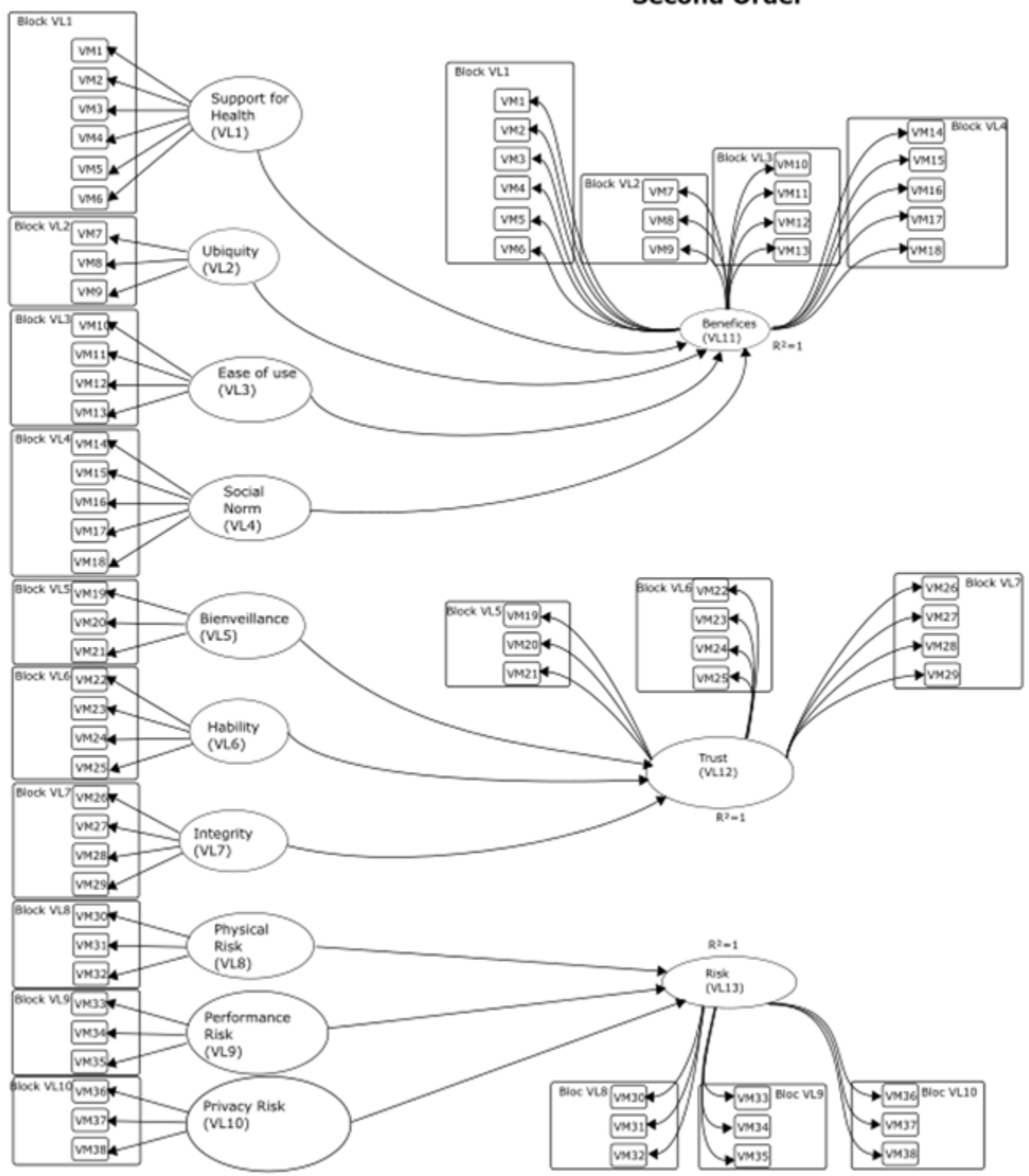




\section{APPENDIX VIII.}

\section{Second Step In The Construction of A Second Order Model}

Figure 6.
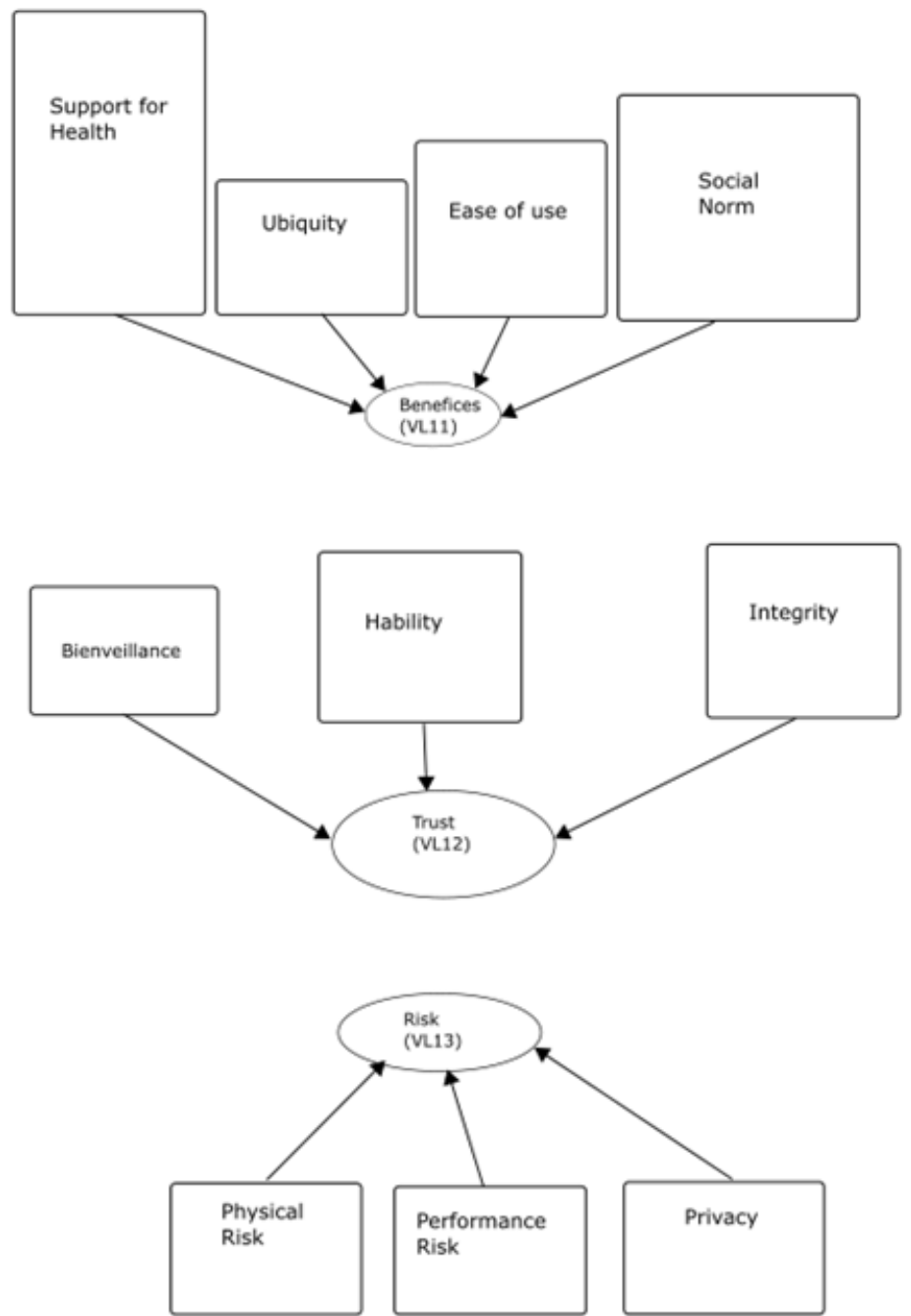


\section{APPENDIX IX.}

\section{Internal Validity}

Table 21.

\begin{tabular}{|c|c|c|c|c|c|c|c|}
\hline Item & Loading & Mean & $\begin{array}{l}\text { Standard } \\
\text { Deviation } \\
\text { (STDEV) }\end{array}$ & T Statistics & rho_A & $\begin{array}{l}\text { Composite } \\
\text { Reliability }\end{array}$ & $\begin{array}{c}\text { Average } \\
\text { Variance } \\
\text { Extracted } \\
(\text { AVE) }\end{array}$ \\
\hline BI1 & 0.955 & 0.955 & 0.007 & 137.368 & \multirow{3}{*}{0.931} & \multirow{3}{*}{0.951} & \multirow{3}{*}{0.867} \\
\hline BI2 & 0.898 & 0.897 & 0.022 & 41.579 & & & \\
\hline BI3 & 0.939 & 0.939 & 0.009 & 104.370 & & & \\
\hline TA1 & 0.798 & 0.799 & 0.030 & 26.900 & \multirow{4}{*}{0.835} & \multirow{4}{*}{0.889} & \multirow{4}{*}{0.668} \\
\hline TA2 & 0.820 & 0.818 & 0.036 & 22.925 & & & \\
\hline TA3 & 0.833 & 0.832 & 0.030 & 27.540 & & & \\
\hline TA4 & 0.817 & 0.817 & 0.028 & 28.991 & & & \\
\hline TB1 & 0.914 & 0.914 & 0.015 & 61.604 & \multirow{3}{*}{0.918} & \multirow{3}{*}{0.947} & \multirow{3}{*}{0.857} \\
\hline TB2 & 0.947 & 0.947 & 0.008 & 112.258 & & & \\
\hline TB3 & 0.917 & 0.916 & 0.016 & 56.061 & & & \\
\hline TI1 & 0.782 & 0.779 & 0.040 & 19.659 & \multirow{4}{*}{0.874} & \multirow{4}{*}{0.913} & \multirow{4}{*}{0.725} \\
\hline TI2 & 0.888 & 0.887 & 0.020 & 44.225 & & & \\
\hline ТI3 & 0.855 & 0.855 & 0.023 & 37.998 & & & \\
\hline TI4 & 0.876 & 0.875 & 0.027 & 31.954 & & & \\
\hline EOU1 & 0.857 & 0.859 & 0.0 .24 & 35.842 & \multirow{4}{*}{0.867} & \multirow{4}{*}{0.906} & \multirow{4}{*}{0.707} \\
\hline EOU2 & 0.790 & 0.785 & 0.050 & 15.734 & & & \\
\hline EOU3 & 0.884 & 0.880 & 0.027 & 32.280 & & & \\
\hline EOU4 & 0.884 & 0.885 & 0.027 & 33.089 & & & \\
\hline SN1 & 0.788 & 0.794 & 0.028 & 28.046 & \multirow{5}{*}{0.840} & \multirow{5}{*}{0.867} & \multirow{5}{*}{0.567} \\
\hline $\mathrm{SN} 2$ & 0.719 & 0.713 & 0.053 & 13.499 & & & \\
\hline SN3 & 0.805 & 0.803 & 0.036 & 22.260 & & & \\
\hline SN4 & 0.712 & 0.706 & 0.051 & 14.000 & & & \\
\hline SN5 & 0.737 & 0.731 & 0.050 & 14.682 & & & \\
\hline PHR1 & 0.777 & 0.776 & 0.037 & 20.957 & \multirow{3}{*}{0.817} & \multirow{3}{*}{0.891} & \multirow{3}{*}{0.732} \\
\hline PHR2 & 0.902 & 0.903 & 0.012 & 75.994 & & & \\
\hline PHR3 & 0.882 & 0.881 & 0.024 & 36.568 & & & \\
\hline PER1 & 0.799 & 0.797 & 0.041 & 19.535 & \multirow{3}{*}{0.611} & \multirow{3}{*}{0.776} & \multirow{3}{*}{0.539} \\
\hline PER2 & 0.598 & 0.582 & 0.115 & 5.193 & & & \\
\hline PER3 & 0.789 & 0.791 & 0.041 & 19.443 & & & \\
\hline PR1 & 0.890 & 0.888 & 0.018 & 48.234 & \multirow{3}{*}{0.905} & \multirow{3}{*}{0.940} & \multirow{3}{*}{0.839} \\
\hline PR2 & 0.937 & 0.936 & 0.010 & 91.278 & & & \\
\hline PR3 & 0.921 & 0.921 & 0.014 & 67.094 & & & \\
\hline
\end{tabular}


Table 21. Continued

\begin{tabular}{|c|c|c|c|c|c|c|c|}
\hline Item & Loading & Mean & $\begin{array}{l}\text { Standard } \\
\text { Deviation } \\
\text { (STDEV) }\end{array}$ & T Statistics & rho_A & $\begin{array}{l}\text { Composite } \\
\text { Reliability }\end{array}$ & $\begin{array}{c}\text { Average } \\
\text { Variance } \\
\text { Extracted } \\
\text { (AVE) }\end{array}$ \\
\hline SH1 & 0.795 & 0.795 & 0.032 & 24.873 & \multirow{6}{*}{0.893} & \multirow{6}{*}{0.914} & \multirow{6}{*}{0.639} \\
\hline SH2 & 0.845 & 0.844 & 0.022 & 38.675 & & & \\
\hline $\mathrm{SH} 3$ & 0.693 & 0.689 & 0.050 & 13.780 & & & \\
\hline SH4 & 0.884 & 0.883 & 0.017 & 53.377 & & & \\
\hline SH5 & 0.825 & 0.823 & 0.027 & 30.863 & & & \\
\hline SH6 & 0.740 & 0.736 & 0.039 & 19.162 & & & \\
\hline UB1 & 0.866 & 0.865 & 0.026 & 33.184 & \multirow{3}{*}{0.784} & \multirow{3}{*}{0.874} & \multirow{3}{*}{0.699} \\
\hline UB2 & 0.886 & 0.886 & 0.021 & 41.695 & & & \\
\hline UB3 & 0.750 & 0.751 & 0.043 & 17.530 & & & \\
\hline \multicolumn{8}{|c|}{$\begin{array}{l}\text { Information on the constructs } \\
\text { BI: Behavior Intention }\end{array}$} \\
\hline \multicolumn{8}{|l|}{ TA: Trust Ability } \\
\hline \multicolumn{8}{|l|}{ TB: Trust Benevolence } \\
\hline \multicolumn{8}{|l|}{ TI: Trust Integrity } \\
\hline \multicolumn{8}{|l|}{ EOU: Ease Of Use } \\
\hline \multicolumn{8}{|l|}{ SN: Social Norms } \\
\hline \multicolumn{8}{|l|}{ PHR: Physical Risk } \\
\hline \multicolumn{8}{|l|}{ PER: Performance Risk } \\
\hline \multicolumn{8}{|l|}{ Private Risk } \\
\hline SH: Support To Health & & & & & & & \\
\hline
\end{tabular}




\section{APPENDIX X.}

\section{Discriminant Validity}

Table 22.

\begin{tabular}{|c|c|c|c|c|c|c|c|c|c|c|c|}
\hline & \begin{tabular}{|l|} 
Behanio \\
unterilo
\end{tabular} & Trust Nbatity & \begin{tabular}{|l|} 
Trust \\
Bencercke \\
nce
\end{tabular} & $\begin{array}{l}\text { Truest } \\
\text { Integerity }\end{array}$ & $\begin{array}{l}\text { Ease of } \\
\text { Use }\end{array}$ & $\begin{array}{l}\text { Social } \\
\text { Norms }\end{array}$ & Ptrysical Rístes & $\begin{array}{l}\text { Performanc } \\
\text { e Risls }\end{array}$ & Privote Rislss & $\begin{array}{l}\text { Suppont To } \\
\text { Ilealth }\end{array}$ & Ubiquilty \\
\hline B11 & 0,055 & 0,317 & 0,055 & 0,205 & 0,176 & 0,333 & $-0,207$ & $-0,053$ & $-0,235$ & 0,376 & 0,319 \\
\hline B12 & 0,900 & 0,304 & 0,066 & 0,197 & 0,132 & 0,413 & $-0,064$ & 0,079 & $-0,115$ & 0,430 & 0,233 \\
\hline B13 & 0,038 & 0,288 & 0,069 & $\mathbf{0}, 213$ & 0,191 & 0,328 & $-0,186$ & $-0,0 \pi 0$ & $-0,204$ & 0,380 & 0,336 \\
\hline IA1 & 0,275 & 0,798 & 0,388 & 0,557 & 0,259 & 0,302 & $-0,134$ & 0,108 & $-0,020$ & 0,433 & 0,302 \\
\hline IA2 & 0,247 & 0,800 & $\mathbf{0 , 3 8 1}$ & $0,52 n$ & 0,154 & 0,335 & $-0,090$ & 0,112 & $-0,044$ & 0,462 & 0,218 \\
\hline IA 3 & 0,342 & D,834 & 0,370 & 0,675 & 0,191 & 0,390 & $-0,089$ & $-0,010$ & $-0,037$ & 0,435 & 0,377 \\
\hline IM & 0,194 & a.817 & 0,315 & 0,567 & $\mathbf{0}, \mathbf{2 1 4}$ & 0,290 & $-0,118$ & 0,062 & $\mathbf{0 , 0 1 3}$ & 0,286 & 0,181 \\
\hline IB1 & $-0,007$ & 0,413 & $\mathbf{0 , 9 1 4}$ & 0,563 & 0,166 & 0,206 & $-0,048$ & 0,115 & 0,046 & 0,372 & 0,178 \\
\hline IB2 & 0,062 & 0,432 & 0,98 & 0,607 & 0,148 & 0,296 & $-0,024$ & 0,139 & 0,101 & 0,355 & 0,254 \\
\hline IB3 & 0,071 & 0,387 & 0,917 & 0,597 & 0,141 & 0,298 & 0,069 & 0,120 & 0,066 & $0,2 \pi$ & 0,185 \\
\hline$\underline{\mathbf{m 1}}$ & 0,109 & $0,4 \pi$ & 0,691 & 0,781 & 0,199 & 0,367 & $-0,041$ & $-0,036$ & $-0,051$ & 0,268 & 0,182 \\
\hline$\underline{n 2}$ & 0,224 & 0,589 & 0,497 & 0,880 & 0,278 & 0,374 & $-0,079$ & $-0,073$ & $-0,005$ & 0,289 & 0,305 \\
\hline$\underline{n 3}$ & 0,211 & 0,688 & 0,477 & 0,856 & 0,200 & 0,368 & $-0,068$ & $-0,0021$ & $-0,009$ & 0,310 & 0,283 \\
\hline$\underline{\mathbf{m}}$ & 0,227 & 0,619 & 0,511 & 0,876 & $\mathbf{0 , 1 8 7}$ & 0,353 & $-0,094$ & $-0,065$ & $-0,111$ & $\mathbf{0 , 3 4 8}$ & $0,2 \pi 0$ \\
\hline EOU1 & 0,169 & 0,201 & 0,130 & 0,210 & 0,857 & 0,055 & $-0,118$ & $-0,033$ & $-0,069$ & 0,155 & 0,520 \\
\hline EOUR & 0,118 & 0,171 & 0,178 & 0,165 & 0,729 & 0,056 & $-0,135$ & 0,085 & 0,012 & 0,190 & 0,351 \\
\hline EOUB & 0,113 & 0,203 & 0,119 & 0,284 & 0,865 & 0,019 & $-0,155$ & 0,006 & $-0,074$ & 0,100 & 0,536 \\
\hline EOU4 & 0,196 & 0,240 & 0,127 & 0,226 & 0.886 & 0,043 & $-0,095$ & 0,000 & $-0,135$ & 0,171 & 0,610 \\
\hline SN1 & $0,3 \mathbf{M A}$ & 0,518 & 0,291 & 0,431 & 0,128 & 0,778 & 0,047 & 0,089 & 0,066 & 0,507 & 0,180 \\
\hline SN2 & 0,246 & 0,162 & 0,151 & 0,258 & $-0, \mathbf{\infty} 1$ & 0,726 & 0,281 & 0,178 & 0,074 & 0,233 & 0,119 \\
\hline SN3 & 0,256 & 0,347 & 0,315 & 0,407 & 0,068 & 0,800 & 0,047 & 0,064 & 0,090 & 0,321 & 0,177 \\
\hline SN4 & 0,307 & 0,195 & 0,143 & 0,214 & 0,010 & 0,713 & 0,180 & 0,072 & 0,099 & 0,264 & 0,081 \\
\hline SNS & 0,272 & 0,188 & 0,164 & 0,243 & $-0,013$ & 0,753 & 0,261 & 0,093 & 0,150 & 0,293 & 0,045 \\
\hline PF需1 & $-0,089$ & $-0,059$ & 0,059 & $-0,015$ & $-0, \times 52$ & 0,129 & 0,776 & 0,294 & 0,347 & $\mathbf{0 , 1 4 4}$ & $-0,005$ \\
\hline PANQ & $-0,206$ & $-0,135$ & $-0,041$ & $-0,114$ & $-0,087$ & 0,160 & 0,903 & 0,220 & 0,357 & $-0,028$ & $-0,152$ \\
\hline PF贯3 & $-0,130$ & $-0,142$ & $-0,076$ & $-0,081$ & $-0,242$ & 0,212 & 0,883 & 0,188 & 0,312 & $-0,067$ & $-0,2026$ \\
\hline PHEFI & $-0,039$ & 0,083 & 0,146 & $-0,047$ & 0,071 & 0,038 & 0,186 & 0,802 & 0,359 & 0,060 & 0,066 \\
\hline P4EFE2 & 0,041 & 0,232 & 0,194 & 0,162 & 0,054 & 0,188 & 0,096 & 0,500 & 0,162 & 0,246 & 0,185 \\
\hline PHEFE & $-0,001$ & $-0,0 \%$ & 0,003 & $-0,157$ & $-0,044$ & 0,049 & 0,287 & 0,790 & 0,283 & 0,049 & $-0,119$ \\
\hline PR1 & $-0,169$ & $-0,068$ & 0,014 & $-0,089$ & $-0,104$ & 0,119 & 0,394 & 0,316 & 0,830 & $-0,017$ & $-0,133$ \\
\hline PRO & $-0,174$ & 0,019 & 0,122 & $-0,043$ & $-0,054$ & 0,160 & 0,360 & 0,370 & 0,937 & 0,087 & $-0,067$ \\
\hline PR3 & $-0,231$ & $-0,038$ & 0,076 & $-0,084$ & $-0,070$ & 0,060 & 0,337 & 0,359 & 0,921 & 0,083 & $-0,114$ \\
\hline SH1 & 0,314 & 0,391 & 0,284 & 0,253 & 0,155 & 0,297 & $-0,844$ & 0,089 & 0,053 & 0,795 & 0,258 \\
\hline SAR & 0,398 & 0,376 & 0,299 & 0,3388 & 0,185 & 0,369 & $-0,056$ & 0,030 & 0,002 & 0,865 & 0,324 \\
\hline SHB & 0,189 & 0,381 & 0,261 & 0,3801 & 0,043 & 0,337 & 0,173 & 0,0866 & 0,171 & 0,003 & 0,008 \\
\hline SAM & 0,313 & 0,361 & 0,271 & 0,2266 & 0,165 & 0,358 & 0,044 & $\mathbf{0 , 1 6 3}$ & 0,099 & 0,884 & 0,278 \\
\hline SHE & 0,386 & 0,415 & 0,268 & 0,393 & 0,179 & 0,394 & 0,058 & 0,100 & $-0,032$ & 0,824 & 0,341 \\
\hline SH6 & 0,407 & 0,467 & 0,349 & 0,302 & 0,130 & 0,393 & 0,051 & 0,152 & 0,001 & $0,7 \pm 0$ & 0,226 \\
\hline UB1 & 0,287 & 0,307 & 0,133 & 0,288 & 0,574 & 0,144 & $-0,118$ & $-0,002$ & $-0,104$ & 0,263 & 0.866 \\
\hline$\underline{\mathrm{UB2}}$ & 0,287 & $0,2 \pi$ & 0,166 & 0,754 & 0,577 & 0,055 & $-0,098$ & $-0,006$ & $-0,141$ & 0,244 & 0886 \\
\hline UB33 & 0,226 & 0,253 & 0,264 & 0,224 & 0,360 & 0,184 & $-0,162$ & 0,104 & $-0,038$ & 0,313 & 0,750 \\
\hline
\end{tabular}


Jean-François De Moya holds a Ph.D. in management sciences from EM Strasbourg Business School An engineer by training, he also has several years of experience in IT development consulting. His research work focuses on the impact of information systems on individuals and particularly on self-quantification behaviors. His work has been published in Information Systems Journal, Revue Française de Gestion, and Management \& Data Science and in the proceedings of leading international conferences, such as the AMCIS and ECIS.

Jessie Pallud is a Full Professor of Management Information Systems at EM Strasbourg Business School in France. She received her dual Ph.D. in Management and Computer Information Systems from Paris Dauphine University and Georgia State University. Her research focuses on IT-related behaviors, user reactions and emotions, humancomputer interaction and technologies of the cultural heritage. She has been a member of program committees and reviewer for national and international conferences in the domains of Information Systems, such as ICIS and AMCIS as reviewer, and ECIS as track chair and Associate Editor. She has published in the European Journal of Information Systems, Journal of Management Information Systems, Information Systems Journal, Information and Management, and in the proceedings of leading international conferences, such as the ICIS, AMCIS and ECIS.

Samuel Fosso Wamba is a Professor at Toulouse Business School. He earned his Ph.D. in industrial engineering at the Polytechnic School of Montreal, Canada. His research interests include IT adoption and use, artificial intelligence in business, business analytics, big data, and open data. He has published papers in: Academy of Management Journal, European Journal of Information Systems, Information Systems Frontiers, International Journal of Production Economics, International Journal of Production Research, Journal of Business Research, Technology Forecasting and Social Change, and Production Planning \& Control. He is the head of the Artificial Intelligence \& Business Analytics Cluster of Toulouse Business School, France. 